University of North Florida

UNIVERSITY of

NORTH FLORIDA

UNF Digital Commons

\title{
Biomarkers of Inflammation in Heart Failure Patients with Reduced and Preserved Ejection Fractions: Multi-Ethnic Study of Atherosclerosis
}

Michelle Lynne Stone

University of North Florida, michelle.lynne.stone@gmail.com

Follow this and additional works at: https://digitalcommons.unf.edu/etd

Part of the Cardiology Commons, Cardiovascular Diseases Commons, Circulatory and Respiratory Physiology Commons, Clinical Epidemiology Commons, Exercise Science Commons, Kinesiotherapy Commons, Physiological Processes Commons, and the Translational Medical Research Commons

\section{Suggested Citation}

Stone, Michelle Lynne, "Biomarkers of Inflammation in Heart Failure Patients with Reduced and Preserved Ejection Fractions: Multi-Ethnic Study of Atherosclerosis" (2020). UNF Graduate Theses and

Dissertations. 943.

https://digitalcommons.unf.edu/etd/943

This Master's Thesis is brought to you for free and open access by the Student Scholarship at UNF Digital Commons. It has been accepted for inclusion in UNF Graduate Theses and Dissertations by an authorized administrator of UNF Digital Commons. For more information, please contact Digital Projects.

(C) 2020 All Rights Reserved

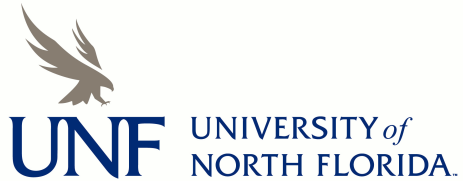


BIOMARKERS OF INFLAMMATION IN HEART FAILURE PATIENTS WITH REDUCED AND PRESERVED EJECTION FRACTIONS: MULTI-ETHNIC STUDY OF ATHEROSCLEROSIS

By

Michelle Lynne Stone

A thesis submitted to the Department of Clinical and Applied Movement Sciences in partial fulfillment of the requirements for the degree of Master of Science in Health, Exercise Science and Chronic Disease

UNIVERSITY OF NORTH FLORIDA

BROOKS COLLEGE OF HEALTH

May 2020 
$\mathrm{X}$

Dr. James R. Churilla, PhD, MPH, MS, RCEP, FACSM

Committee Chairperson

$\mathrm{X}$

Dr. Tammie M. Johnson, DrPH, MPH

Committee Member

$\mathrm{X}$

Dr. Robert J. Chilton, DO, FACC, FAHA

Committee Member

$\mathrm{X}$

Dr. Clinton Brawner, PhD, RCEP, FACSM

Committee Member

$\mathrm{X}$

Dr. Michael R. Richardson, PhD, MSH, ACSM EP-C

Committee Member 


\section{Dedication and Acknowledgements}

These past two-years have required a strong commitment and many sacrifices throughout. I cannot thank my family and my partner enough for their commitment to supporting me. This thesis project is dedicated to my partner, Travis.

Travis, thank you for being there for me from the first day of graduate school to the last. Your patience, encouragement, sense of humor, and cooking skills have kept me fed and focused for every task. Thank you for always understanding and supporting my sacrifices and for making sacrifices yourself for me. You helped me make this project possible.

I would also like to thank Dr. Richardson, $\mathrm{PhD}, \mathrm{MSH}, \mathrm{EP}-\mathrm{C}$ for his constant mentorship over the past four years. You have been a role model and source of inspiration to me. Thank you for all of the academic opportunities and words of wisdom that have led me to where I am today.

Thank you Dr. Clinton A. Brawner PhD, RCEP, FACSM, Dr. Robert J. Chilton, DO, FACC, FAHA and Dr. Tammie M. Johnson, DrPH, MPH for providing your time, leadership and overall expertise to this project. Thank you also to my fellow graduate research assistants Bethany Rand, Chakene Rogers and Daniela Charry Sergura for your friendship, support and encouragement.

Finally, I would like to thank my committee chairperson and mentor throughout graduate school Dr. James R. Churilla, PhD, MPH, MS, RCEP, FACSM. Thank you for always challenging me and shaping me into a more confident student, teacher, and researcher. Your constant guidance, leadership, and high expectations have allowed me to push myself to do more than I thought possible. I will always be grateful for these past two years that I have been under your mentorship. Thank you. 


\section{Table of Contents}

List of Tables.....................................................................................

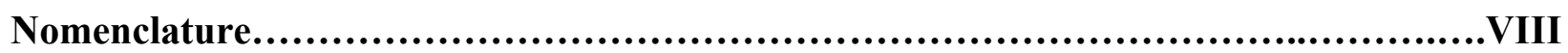

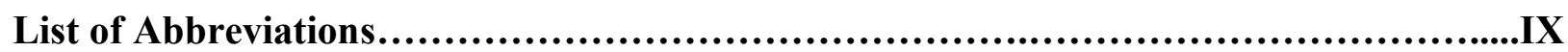

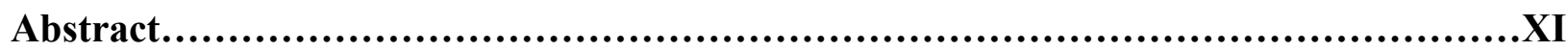

Chapter One: Introduction....................................................................

Background..........................................................................

Heart Failure........................................................................ 3

Inflammatory Biomarkers ................................................

Focused Literature Review...........................................................

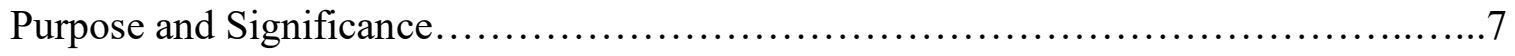

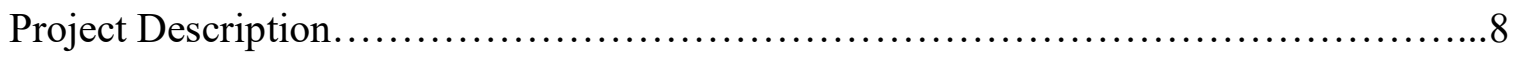

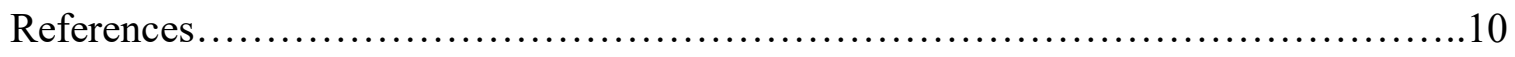

Chapter Two: Review of Literature..........................................................17

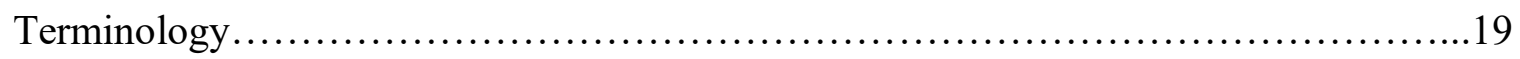

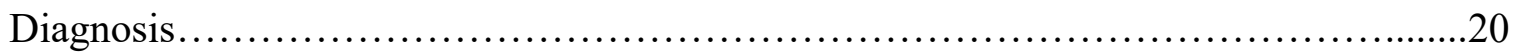

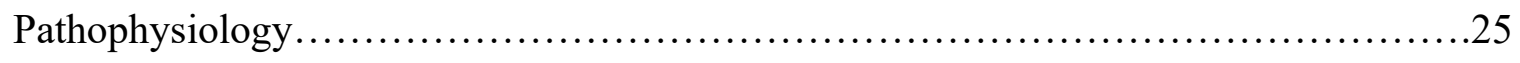

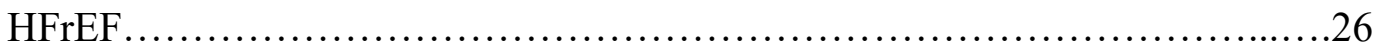

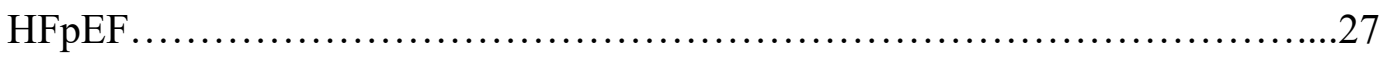

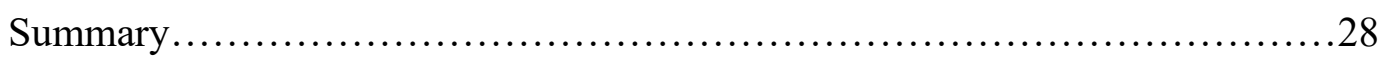

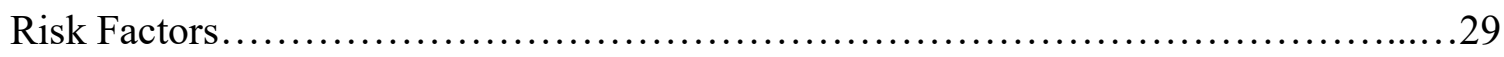

Heart Failure and Inflammation......................................................33

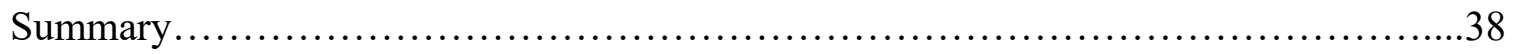




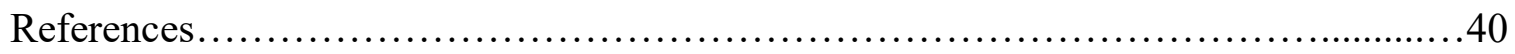

Chapter Three: Methodology ...............................................................49

Data Collection.................................................................... 50

Primary Dependent Variables: Heart Failure..............................................52

Primary Independent Variables: Inflammatory Markers..................................................53

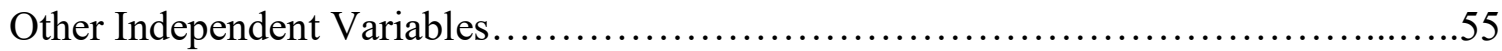

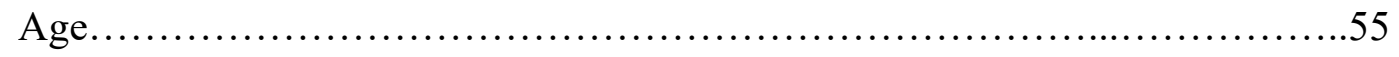

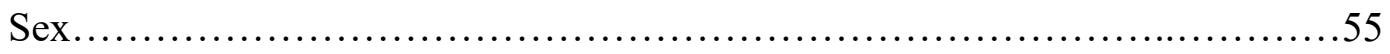

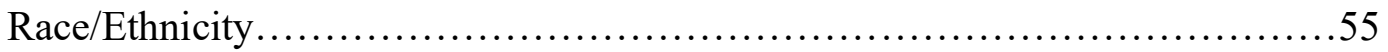

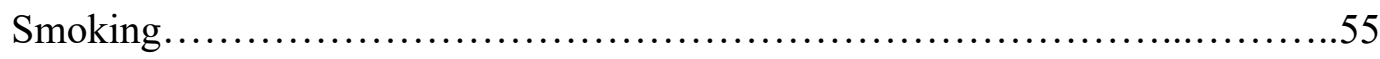

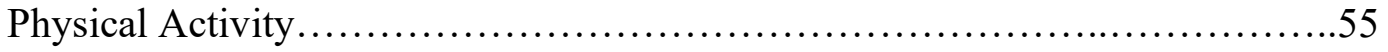

Waist Circumference....................................................56

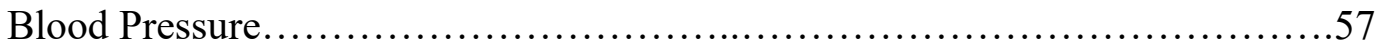

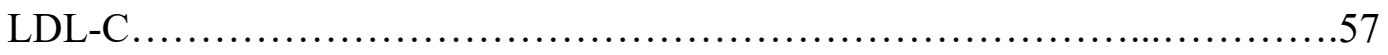

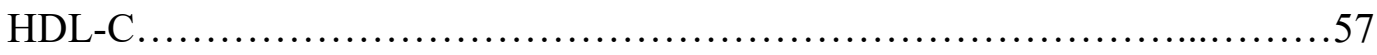

Triglycerides......................................................... 57

Family History of MI................................................. 58

Anti-inflammatory Medications..........................................58

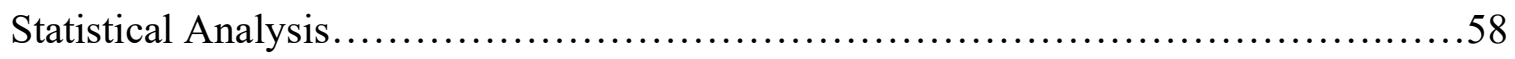

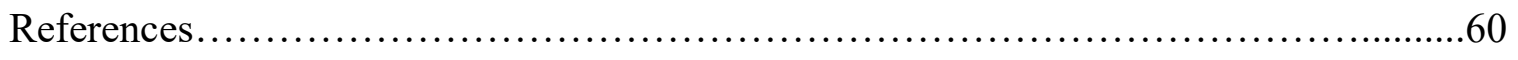

Chapter Four: Manuscript............................................................61

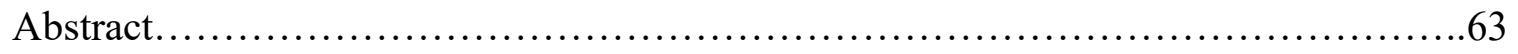

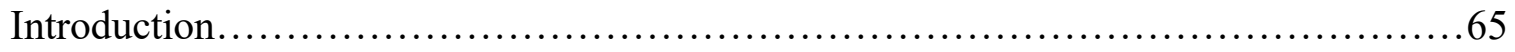




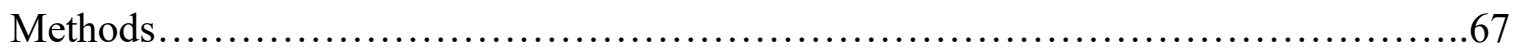

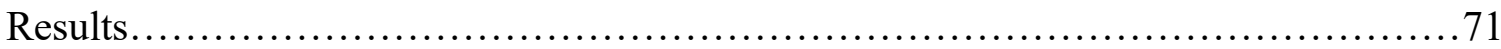

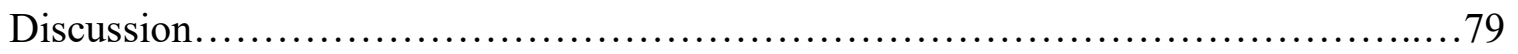

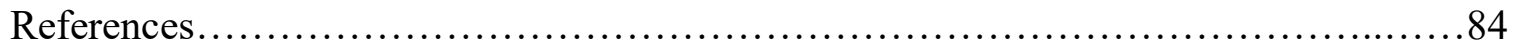

Appendices..............................................................................................................................................92

Appendix A: University of North Florida IRB Approval Letter.........................93

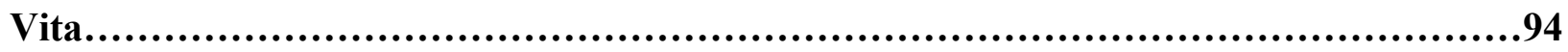




\section{List of Tables}

Tables

Page

\section{Chapter Two: Review of Literature}

1. Framingham Clinical Diagnostic Criteria for Congestive Heart Failure.................21

2. Definitions of HFpEF Used in Epidemiological Studies of HFpEF....................24

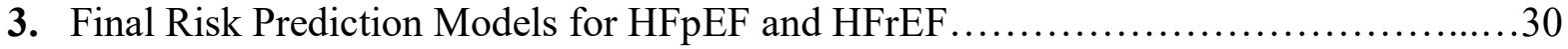

4. Differential Effects of Risk Factors on HFpEF vs HFrEF......................... 31

5. Peripheral Levels of Cytokines and Cytokine Receptors in Heart Failure...............37

6. Role of Inflammatory Biomarkers in Heart Failure...................................... 38

\section{Chapter Four: Manuscript}

1. Baseline Characteristics of U.S. Adults by HF Status................................... 72

2. HRs for Incident HF, HFrEF, and HFpEF in U.S. Adults with Elevated Inflammatory

Biomarkers............................................................ 74

3. HRs for Incident HF in U.S. Adults with Elevated Inflammatory Markers..............76

4. HRs for Incident HFrEF in U.S. Adults with Elevated Inflammatory Markers..........77

5. HRs for Incident HFpEF in U.S. Adults with Elevated Inflammatory Markers...........79 


\section{Nomenclature}

$\begin{array}{ll}\mathrm{cm} & \text { centimeter } \\ \mathrm{MET} \cdot \mathrm{min} / \mathrm{wk} & \text { MET minutes per week } \\ \mathrm{mg} / \mathrm{dL} & \text { milligrams per deciliter } \\ \mathrm{mg} / \mathrm{L} & \text { milligrams per liter } \\ \mathrm{mmHg} & \text { millimeters of mercury } \\ \mathrm{pg} / \mathrm{mL} & \text { picogram per liter }\end{array}$




\section{List of Abbreviations}

\begin{tabular}{|c|c|}
\hline AHA & American Heart Association \\
\hline $\mathrm{BP}$ & blood pressure \\
\hline $\mathrm{CI}$ & confidence interval \\
\hline CVD & cardiovascular disease \\
\hline CHD & coronary heart disease \\
\hline $\mathrm{CHF}$ & congestive heart failure \\
\hline DHF & diastolic heart failure \\
\hline $\mathrm{EF}$ & ejection fraction \\
\hline FHS & Framingham Heart Study \\
\hline $\mathrm{HF}$ & heart failure \\
\hline HFpEF & heart failure with preserved ejection fraction \\
\hline HFrEF & heart failure with reduced ejection fraction \\
\hline HDL & high density lipoprotein \\
\hline HTN & hypertension \\
\hline HR & hazard ratio \\
\hline LDL & low density lipoprotein \\
\hline LV & left ventricle/left ventricular \\
\hline LVEF & left ventricular ejection fraction \\
\hline MESA & Multi-Ethnic Study of Atherosclerosis \\
\hline MET & metabolic equivalent \\
\hline MI & myocardial infarction \\
\hline PA & physical activity \\
\hline
\end{tabular}


SAS statistical analysis software

SHF systolic heart failure

WC waist circumference 


\begin{abstract}
Purpose: Examine the relationships between high-sensitivity C-reactive protein (hsCRP), interleukin-6 (IL-6), and soluble tumor necrosis factor- $\alpha$ receptor-1 (sTNF-R1) and the cumulative risk of heart failure with reduced (HFrEF) and preserved (HFpEF) ejection fractions in a diverse, population-based sample.
\end{abstract}

Methods: Study sample included 6,814 adult (45-84 years of age) men and women who participated in the Multi-Ethnic Study of Atherosclerosis and were free of cardiovascular disease at baseline. Cox regression was used to calculate the hazard ratios (HR) associated with elevated baseline hs-CRP $(>3-10$ $\mathrm{mg} / \mathrm{L})$, IL-6 ( $>75$ th percentile) and sTNF-R1 ( $>75$ th percentile) and risk of overall HF, HFrEF (ejection fraction $[\mathrm{EF}]<50 \%$ ), and $\mathrm{HFpEF}(\mathrm{EF} \geq 50 \%)$.

Results: During $\sim 11.2$ years of follow-up there were 178 incident HF diagnoses. Elevated hs-CRP, IL-6 and sTNF-R1 were associated with a significant increased risk of HF overall (HR 1.76; 95\% Confidence interval [CI] 1.222.52, HR 1.57; 95\% 1.07-2.30, and HR 1.91; 95\% CI 1.08-3.38, respectively). Elevated hs-CRP was a significant predictor in both $\mathrm{HFrEF}$ and HFpEF (HR 2.05; 95\% CI 1.26-3.35, and HR 1.89; 95\% CI 1.09-3.28, respectively). Baseline IL-6 concentrations were significantly associated with increased risk of HFrEF in nonsmokers only (HR 2.33; 95\% CI 1.045.23) and of HFpEF in African Americans only (HR 5.89; 95\% CI 1.5222.80). 
Conclusion: In a diverse sample of U.S. adults, elevated hs-CRP, IL-6 and sTNF-R1 were significant predictors of HF. Furthermore, both hs-CRP and IL-6 were significant predictors in HFrEF and HFpEF. 
Chapter One: Introduction 
Heart failure (HF) is a condition characterized by an inability of the heart to supply sufficient blood to the body to meet metabolic demands or accommodate systemic venous return (1). This disease manifests either due to failure of the left ventricle (LV) to fill with enough blood or to contract with enough force or, occasionally, a combination of the two $(2,3)$. The inability to contract with sufficient force often results in a reduced percentage of blood ejected from the LV, also known as the ejection fraction (EF). These patients are considered to have heart failure with reduced ejection fraction (HFrEF). Those with an inability to properly fill the LV can often still eject a volume of blood that is proportional to their end diastolic volume, resulting in a normal, or preserved, EF. Accordingly, these patients are considered to have heart failure with preserved ejection fraction (HFpEF). Although these subtypes share several similarities, recent literature has demonstrated distinct differences in the epidemiology, etiology, treatment, and prognosis $(4,5)$ of HFrEF and HFpEF. Chronic inflammation, characterized using several different inflammatory biomarkers, has been positively associated with HF incidence, severity, and prognosis. These biomarkers include C-reactive protein (CRP), interleukin-6 (IL-6), and soluble tumor necrosis factor- $\alpha$ receptor-1 (sTNF-R1) (6-10).

This chapter includes relevant background information pertaining to HF, CRP, IL-6, and sTNF-R1. This is followed by a focused review of the existing literature regarding the relationship between these variables. The chapter concludes with the purpose and significance of the research, a project description, and limitations inherent to the study design. 


\section{BACKGROUND}

\section{HEART FAILURE}

The prevalence of HF in the adult population ranges from 1 to $3 \%(5,11-13)$ but increases to upwards of $10 \%$ in older populations (13-15). The prevalence of HFpEF among those with HF varies widely depending on several factors including the diagnostic criteria, clinical setting, age and sex of the population, and year of publication (2). Nonetheless, most investigations have found the prevalence of HFpEF in this population is about $50 \%(16-20)$.

The age- and sex-adjusted incidence of HF declined 37\% from 2000 to 2010 with a much greater rate reduction seen in those with $\operatorname{HFrEF}(-45 \%)$ than $\mathrm{HFpEF}(-28 \%)(P$ for interaction $=$ $=0.08)$ (21). However, the prevalence of HF is expected to increase $23 \%$ equating to a $46 \%$ increase in the number of Americans living with HF from 2012 to 2030 (22). The increasing prevalence is largely due to the growth of the aging population as well as improvements in lifeprolonging HF therapy $(2,11,23)$. Despite these advancements, mortality rates remain high at about 19.9 per 100,000 (24) with little or no improvement over the past couple of decades and a 5-year survival rate of $\sim 50 \%(21,25,26)$.

Though it is believed the first case of HF was identified roughly 3,500 years ago, it was not until the 1950's that the idea of cardiac contractility came about and was later believed to account for changes observed in HF (27). Research then focused on understanding reduced contractility and developing ionotropic medications that would increase EF in these patients. Until the late 1980-1990's, LV systolic dysfunction was considered a prerequisite for HF however, repeated observations of HF without LV systolic dysfunction lead to the recognition of heart failure with LV diastolic dysfunction $(5,27-29)$. The two subtypes were originally termed systolic and diastolic HF however, the preferred terminology today is HFrEF and HFpEF, 
respectively, as many HF patients demonstrate some degree of both systolic and diastolic dysfunction $(2,3)$ but can still be distinguished by left ventricular ejection fraction (LVEF) (3, 4).

Despite the recognition of two distinct HF subtypes over two decades ago, a harmonious definition for HFrEF and HFpEF has yet to be established $(2,3,30)$. In the most recent guideline for the management of HF (3) set out by the American College of Cardiology Foundation (ACCF)/American Heart Association (AHA), HF was defined as, "a complex clinical syndrome that results from any structural or functional impairment of ventricular filling or ejection of blood." Impairments that may lead to HF include, but are not limited to, abnormalities of the myocardium, endocardium, pericardium, heart valves, great vessels, or some metabolic abnormalities. However, most symptomatic patients have LV myocardial dysfunction. The ACCF/AHA also emphasized that LV dysfunction and cardiomyopathy are not interchangeable with HF but instead they should be used to describe possible reasons for the development of systolic or diastolic LV dysfunction. In the literature, HF subtypes have been classified by various LVEF cutpoints however, the most recent definition from the ACCF/AHA classifies $\mathrm{HFrEF}$ as an $\mathrm{EF} \leq 40 \%$ and $\mathrm{HFpEF}$ as an $\mathrm{EF} \geq 50 \%$. Ejection fraction values ranging from 41 49\% are considered heart failure with mid-range ejection fraction (HFmrEF).

Though useful for defining HFrEF and HFpEF, more is required for a diagnosis than EF. Several epidemiological studies have developed their own diagnostic criteria for diagnosing HF that have continued to be used throughout the years (31-34). These criteria include a combination of determinants include signs and symptoms, medical history review, radiographic evidence, and response to therapy however, they do not differentiate between HFrEF and HFpEF. In response, studies that have aimed to differentiate between HFrEF and HFpEF have 
modified the previously existing criteria to include an EF cut point (29). Several serological markers, including biomarkers of inflammation, have been implicated to strengthen the HF diagnosis however; there is a need to investigate novel biomarkers for the evaluation and management of patients with HF, particularly in $\mathrm{HFpEF}$ (35-37).

\section{INFLAMMATORY BIOMARKERS}

\section{C-Reactive Protein}

C-reactive protein $(\mathrm{CRP})$ is an acute phase plasma protein produced by the liver in response to inflammation (38). Activation of CRP in hepatocytes is primarily regulated at the transcriptional level by interleukin-6 (IL-6) but interleukin-1 (IL-1) and tumor necrosis factor- $\alpha$ (TNF- $\alpha$ ) can also regulate CRP to some degree (38-40). There is also evidence of extrahepatic production of CRP by lymphocytes, neurons, renal cells and in the atherosclerotic lesion, specifically by smooth muscle and macrophages $(39,41)$.

In adults with no prior history of cardiovascular disease, a single, non-fasting measure of CRP can be a strong predictor of future vascular events even after controlling for traditional risk factors including age, smoking, cholesterol, blood pressure, and diabetes (42). C-reactive protein has been shown to contribute to atherogenesis and predict incident myocardial infarction, stroke, peripheral artery disease, and sudden death $(39,42)$. "High-sensitivity" assays are recommended for the measurement of CRP as these are designed to detect CRP concentrations across a lownormal range and are widely available (42).

In a 2003 statement (43), the Centers for Disease Control and the AHA recommended using a high-sensitivity C-reactive protein (hs-CRP) cut point of $>3 \mathrm{mg} / \mathrm{L}$ to define high risk in the adult population. Being a biomarker of inflammation, CRP concentrations can be elevated 
over 100-fold in the presence of major infections, trauma, or acute hospitalizations. For this reason, it is also recommended that concentrations $>10 \mathrm{mg} / \mathrm{L}$ should be discarded.

\section{Interleukin-6}

Interleukin-6 (IL-6) is a proinflammatory cytokine secreted by various cells including activated macrophages and lymphocytes (40). Most cytokines function at the paracrine/autocrine level however, IL-6 is unique in that it is predominately a circulatory molecule therefore its major actions take place away from its site of origin. Secretion and expression of IL-6 is induced by IL-1 and TNF- $\alpha$ (44) and IL- 6 can, in turn, regulate the activity of IL-1 by directly inducing the release of its receptor antagonist and TNF- $\alpha$. Circulating concentrations of IL-6 increase with obesity and in the presence of systemic infection or inflammation $(40,45)$. In healthy individuals, as much as one-third of total circulating IL-6 concentrations are estimated to originate from adipose tissue.

Interleukin-6 is sometimes referred to as a "remodeling" biomarker as it can directly affect cell-to-cell communication between myocytes and fibroblasts, and changes in concentration are associated with changes in cardiac extracellular matrix and function (37). In a prospective study of older adults without baseline cardiovascular disease (10), IL-6 was a significant predictor of incident coronary heart disease, stroke, and congestive HF. Immunosorbent assays are often used to measure IL-6 levels and high risk is often determined by the sample-specific upper tertile $(9,10,46)$.

\section{Soluble Tumor Necrosis Factor-a Receptor-1}

Tumor necrosis factor- $\alpha$ is the smaller and more abundant isoform of tumor necrosis factor. It is a proinflammatory cytokine produced primarily by macrophages in response to inflammation however, adipocytes have also been shown to express TNF- $\alpha$ (47). Two distinct 
surface receptors, TNFR-1 and TNFR-2, mediate the effects of TNF and exist in either

membrane-bound or soluble forms (48). Though the extracellular domains of these receptors are conserved, the cytoplasmic portions are not, suggesting differing downstream processes. Both receptors have been found in human myocytes with TNFR-1 being the predominate subtype in most cells, including the heart $(48,49)$. Binding of TNF- $\alpha$ to TNFR-1 induces an inflammatory response in the myocytes. Additionally, the extracellular portion of the receptor can then be cleaved by a proteolytic enzyme, releasing soluble tumor necrosis factor- $\alpha$ recptor-1 (sTNF-R1) which can then diffuse into circulation (36). Elevated sTNF-R1 has been significantly associated with an increased risk of HF across whites and blacks, and males and females (50).

\section{FOCUSED LITERATURE REVIEW}

Although existing literature has demonstrated an increased risk of HF in those with elevated hs-CRP $(51,52)$, IL-6 $(9,51)$ and sTNF-R1 $(50)$, there are fewer investigations that have determined these relationships in HFrEF and HFpEF. Furthermore, there is limited data examining these relationships in multi-ethnic, diverse samples.

\section{PURPOSE AND SIGNIFICANCE}

The purpose of this study was to examine the relationship between elevated hs-CRP, IL-6, and sTNF-R1 and the cumulative risk of HFrEF and HFpEF in a diverse sample of U.S. adults 45-84 years of age. The specific research question addressed was:

1. Is there an association between elevated hs-CRP, IL-6, or sTNF-R1 and the cumulative risk of HFrEF or HFpEF? 
To the extent of our knowledge, this is the first study to examine the relationship between elevated hs-CRP, IL-6 and sTNF-R1 and incidence HFrEF and HFpEF in a diverse sample of U.S. adults 45-84 years of age who participated in the Multi-Ethnic Study of Atherosclerosis (MESA).

\section{PROJECT DESCRIPTION}

The MESA (53) is a community-based, multi-center, prospective cohort study including 6,814 men and women 45-84 years of age who were free of clinical cardiovascular disease at baseline. Multivariable hazard ratios were calculated using the proportional hazards regression procedure to determine the cumulative risk of HFrEF and HFpEF according to baseline hs-CRP, IL-6 and sTNF-R1. Limitations include:

1. Biomarkers of inflammation were measured at a single time point; therefore, it is unclear if elevated concentrations were indicative of acute or chronic inflammation.

2. Inherent in the design of the MESA, the diverse, multi-ethnic sample was not representative of the U.S. population, affecting the generalizability of the results.

3. The sample size of those with HF was relatively small, especially when categorized by HFrEF and HFpEF. Additionally, sample sizes were even smaller for variables such as sTNF-R1 in which concentrations were only analyzed in a subset of the sample.

4. Self-reported data was used for some of the covariates which is subject to recall bias and self-report bias.

5. There is a potential for residual confounding in which there may be additional confounding factors that were not included. 
6. Incident $\mathrm{HF}$ was defined as time to first $\mathrm{HF}$ event, therefore subsequent $\mathrm{HF}$ events and potential changes in EF over time were not included in the analysis.

7. Individuals without sufficient $\mathrm{EF}$ data at the time of their first HF event were not included in the analyses. 


\section{REFERENCES}

1. Kemp CD, Conte JV. The pathophysiology of heart failure. Cardiovascular Pathology. $2012 ; 21(5): 365-371$.

2. Ponikowski P, Voors AA, Anker SD, et al. 2016 ESC guidelines for the diagnosis and treatment of acute and chronic heart failure: The task force for the diagnosis and treatment of acute and chronic heart failure of the European society of cardiology (ESC)developed with the special contribution of the heart failure association (HFA) of the ESC. European Heart Journal. 2016;37(27):2129-2200.

3. Yancy C, Jessup M, Bozkurt B, et al. 2013 ACCF/AHA guideline for the management of heart failure: Executive summary: A report of the American college of cardiology foundation/American heart association task force on practice guidelines. Circulation. 2013;128(16):1810-1852.

4. Ho JE, Enserro D, Brouwers FP, et al. Predicting heart failure with preserved and reduced ejection fraction: The international collaboration on heart failure subtypes. Circulation-Heart failure. 2016;9(6).

5. Gladden J, Chaanine A, Redfield M. Heart failure with preserved ejection fraction. Annual Review of Medicine. 2018;69:65-79.

6. Carnes J, Gordon G. Biomarkers in heart failure with preserved ejection fraction: An update on progress and future challenges. Heart, Lung and Circulation. 2020;29(1):62-68.

7. Bozkurt B, Mann DL, Deswal A. Biomarkers of inflammation in heart failure. Heart Failure Reviews. 2010;15(4):331-341. 
8. Bahrami H, Bluemke DA, Kronmal R, et al. Novel metabolic risk factors for incident heart failure and their relationship with obesity: The MESA (multi-ethnic study of atherosclerosis) study. Journal of the American College of Cardiology. 2008;51(18):1775-1783.

9. Vasan RS, Sullivan LM, Roubenoff R, et al. Inflammatory markers and risk of heart failure in elderly subjects without prior myocardial infarction: The Framingham heart study. Circulation. 2003;107(11):1486-1491.

10. Cesari M, Penninx, Brenda W. J. H, Newman AB, et al. Inflammatory markers and onset of cardiovascular events: Results from the health ABC study. Circulation. 2003;108(19):23172322.

11. Komanduri S, Jadhao Y, Guduru SS, Cheriyath P, Wert Y. Prevalence and risk factors of heart failure in the USA: NHANES 2013 - 2014 epidemiological follow-up study. Journal of Community Hospital Internal Medicine Perspectives. 2017;7(1):15-20.

12. van Riet, Evelien E S, Hoes AW, Wagenaar KP, Limburg A, Landman MAJ, Rutten FH. Epidemiology of heart failure: The prevalence of heart failure and ventricular dysfunction in older adults over time. A systematic review. European Journal of Heart Failure. 2016;18(3):242-252.

13. Galasko GIW, Senior R, Lahiri A. Ethnic differences in the prevalence and aetiology of left ventricular systolic dysfunction in the community: The harrow heart failure watch. Heart. 2005;91(5):595-600.

14. Dickstein K, Cohen-Solal A, Filippatos G, et al. ESC guidelines for the diagnosis and treatment of acute and chronic heart failure 2008. European Journal of Heart Failure. 2008;10(10):933-989. 
15. Alehagen, Urban, $\mathrm{PhD}, \mathrm{MD}$, Ericsson A, MD, Dahlström, Ulf, PhD, MD. Are there any significant differences between females and males in the management of heart failure? gender aspects of an elderly population with symptoms associated with heart failure. Journal of Cardiac Failure. 2009;15(6):501-507.

16. Bursi F, Weston SA, Redfield MM, et al. Systolic and diastolic heart failure in the community. JAMA. 2006;296(18):2209-2216.

17. Vasan RS, Larson MG, Benjamin EJ, Evans JC, Reiss CK, Levy D. Congestive heart failure in subjects with normal versus reduced left ventricular ejection fraction: Prevalence and mortality in a population-based cohort. Journal of the American College of Cardiology. 1999;33(7):1948.

18. Kitzman DW, Gardin JM, Gottdiener JS, et al. Importance of heart failure with preserved systolic function in patients $\geq 65$ years of age. The American Journal of Cardiology. 2001;87(4):413-419.

19. Devereux RB, Roman MJ, Liu JE, et al. Congestive heart failure despite normal left ventricular systolic function in a population-based sample: The strong heart study. The American Journal of Cardiology. 2000;86(10):1090-1096.

20. Kupari M, Lindroos M, Iivanainen Am, Heikkilä J, Tilvis R. Congestive heart failure in old age: Prevalence, mechanisms and 4-year prognosis in the Helsinki ageing study. Journal of Internal Medicine. 1997;241(5):387-394.

21. Gerber Y, Weston SA, Redfield MM, et al. A contemporary appraisal of the heart failure epidemic in Olmsted county, Minnesota, 2000 to 2010. JAMA Internal Medicine. 2015;175(6):996-1004. 
22. Heidenreich PA, Albert NM, Allen LA, et al. Forecasting the impact of heart failure in the united states: A policy statement from the American Heart Association. Circulation. Heart failure. 2013;6(3):606-619.

23. Bytyçi I, Bajraktari G. Mortality in heart failure patients. Anatolian Journal of Cardiology. 2015;15(1):63-68.

24. Vasan RS, Zuo Y, Kalesan B. Divergent temporal trends in morbidity and mortality related to heart failure and atrial fibrillation: Age, sex, race, and geographic differences in the united states, 1991-2015. Journal of the American Heart Association. 2019;8(8):e10756.

25. Levy D, Kenchaiah S, Larson MG, et al. Long-term trends in the incidence of and survival with heart failure. The New England Journal of Medicine. 2002;347(18):1397-1402.

26. Loehr LR, Rosamond WD, Chang PP, Folsom AR, Chambless LE. Heart failure incidence and survival (from the Atherosclerosis Risk in Communities Study) American Journal of Cardiology. 2008;101:1016-1022.

27. Ferrari R, Balla C, Fucili A. Heart failure: An historical perspective. European Heart Journal Supplements. 2016;18(suppl G):G3-G10.

28. Herrmann G, Decherd G. The chemical nature of heart failure. Annals of Internal Medicine. $1939 ; 12(8): 1233$.

29. Pfeffer M, Shah A, Borlaug B. Heart failure with preserved ejection fraction in perspective. Circulation Research. 2019;124(11):1598-1617.

30. Upadhya B, Kitzman DW. Heart failure with preserved ejection fraction: New approaches to diagnosis and management. Clinical Cardiology. 2020;43(2):145-155.

31. Dawber TR, Kannel WB, Lyell LP. An approach to longitudinal studies in a community: The Framingham study. Annals of the New York Academy of Sciences. 1963;107(2):539-556. 
32. Carlson KJ, Lee DC-, Goroll AH, Leahy M, Johnson RA. An analysis of physicians' reasons for prescribing long-term digitalis therapy in outpatients. Journal of Chronic Diseases. 1985;38(9):733-739.

33. Schellenbaum GD, Rea TD, Heckbert SR, et al. Survival associated with two sets of diagnostic criteria for congestive heart failure. American Journal of Epidemiology. 2004;160(7):628-635.

34. Eriksson H, Caidahl K, Larsson B, et al. Cardiac and pulmonary causes of dyspnoeavalidation of a scoring test for clinical-epidemiological use: The study of men born in 1913 . European heart journal. 1987;8(9):1007-1014.

35. Gladden J, Linke W, Redfield M. Heart failure with preserved ejection fraction. Circulation. Heart failure. 2014;466(6):1037-1053.

36. Chow SL, Maisel AS, Anand I, et al. Role of biomarkers for the prevention, assessment, and management of heart failure A scientific statement from the American heart association. Circulation. 2017;135(22):E1054-E1091.

37. van Kimmenade, Roland R J, Januzzi J, James L. Emerging biomarkers in heart failure. Clinical Chemistry. 2012;58(1):127-138.

38. Black S, Kushner I, Samols D. C-reactive protein. Journal of Biological Chemistry. 2004;279(47):48487-48490.

39. Jialal I, Devaraj S, Venugopal SK. C-reactive protein: Risk marker or mediator in atherothrombosis? Hypertension. 2004;44(1):6-11.

40. Yudkin JS, Kumari M, Humphries SE, Mohamed-Ali V. Inflammation, obesity, stress and coronary heart disease: Is interleukin-6 the link? Atherosclerosis. 2000;148(2):209-214. 
41. Kuta AE, Baum LL. C-reactive protein is produced by a small number of normal human peripheral blood lymphocytes. The Journal of Experimental Medicine. 1986;164(1):321-326.

42. Ridker PM. Clinical application of C-reactive protein for cardiovascular disease detection and prevention. Circulation. 2003;107(3):363-369.

43. Pearson TA, Mensah GA, Alexander RW, et al. Markers of inflammation and cardiovascular disease: Application to clinical and public health practice: A statement for healthcare professionals from the centers for disease control and prevention and the American Heart Association. Circulation. 2003;107(3):499-511.

44. Pang, G., Couch, L., Batey, R., Clancy, R., \& Cripps, A. (1994). GM-CSF, IL-1 alpha, IL-1 beta, IL-6, IL-8, IL-10, ICAM-1 and VCAM-1 gene expression and cytokine production in human duodenal fibroblasts stimulated with lipopolysaccharide, IL-1 alpha and TNFalpha. Clinical and Experimental Immunology, 96(3), 437.

45. Mohamed-Ali V, Goodrick S, Rawesh A, et al. Subcutaneous adipose tissue releases interleukin-6, but not tumor necrosis factor- $\alpha$, in Vivo1. The Journal of Clinical Endocrinology \& Metabolism. 1997;82(12):4196-4200.

46. Palta P, Xue Q, Deal JA, Fried LP, Walston JD, Carlson MC. Interleukin-6 and C-reactive protein levels and 9-year cognitive decline in community-dwelling older women: The women's health and aging study II. The Journals of Gerontology: Series A. 2015;70(7):873878.

47. Hotamisligil GS, Arner P, Caro JF, Atkinson RL, Spiegelman BM. Increased adipose tissue expression of tumor necrosis factor-alpha in human obesity and insulin resistance. The Journal of Clinical Investigation. 1995;95(5):2409-2415. 
48. Sack MN. Tumor necrosis factor- $\alpha$ in cardiovascular biology and the potential role for antitumor necrosis factor- $\alpha$ therapy in heart disease. Pharmacology and Therapeutics. 2002;94(1):123-135.

49. Torre-Amione G, Kapadia S, Benedict C, Oral H, Young JB, Mann DL. Proinflammatory cytokine levels in patients with depressed left ventricular ejection fraction: A report from the studies of left ventricular dysfunction (SOLVD). Journal of the American College of Cardiology. 1996;27(5):1201.

50. Marti CN, Khan H, Mann DL, et al. Soluble tumor necrosis factor receptors and heart failure risk in older adults: Health, aging, and body composition (health ABC) study. CirculationHeart Failure. 2014;7(1):5-11.

51. Bahrami H, Kronmal R, Bluemke DA, et al. Differences in the incidence of congestive heart failure by ethnicity: The multi-ethnic study of atherosclerosis. Archives of Internal Medicine. 2008;168(19):2138-2145.

52. Cainzos-Achirica M, Miedema MD, Mcevoy JW, et al. The prognostic value of high sensitivity C-reactive protein in a multi-ethnic population after more than 10 years of followup: The multi-ethnic study of atherosclerosis (MESA). International Journal of Cardiology. $2018 ; 264: 158-164$.

53. Bild DE, Bluemke DA, Burke GL, et al. Multi-ethnic study of atherosclerosis: Objectives and design. American Journal of Epidemiology. 2002;156(9):871-881. 
Chapter Two: Review of Literature 
Heart failure (HF) is a complex clinical syndrome characterized by an inability of the heart to deliver enough blood to meet metabolic demands or doing so only at the cost of increased filling pressures $(1,2)$. This results from injury or stress to the myocardium which often occurs due to ischemic heart disease, hypertension, chronic obstructive pulmonary disease, rheumatic heart disease and diabetes $(3,4)$. When the heart fails to compensate for injury, signs and symptoms of HF that develop include dyspnea, fatigue, and fluid retention leading to pulmonary congestion and/or peripheral edema $(2,5)$. Though commonly associated with congestion, exercise tolerance is often limited in HF patients with and without evidence of fluid retention (2). Underlying abnormalities of the myocardium are common in HF and often result in left ventricular (LV) systolic and/or diastolic dysfunction, however, abnormalities of the pericardium, endocardium, heart rhythm, and conduction are also observed $(5,6)$. One of the most common noninvasive techniques used to determine the presence of LV systolic or diastolic dysfunction is by Doppler echocardiography (7). Also, this method is often used to determine left ventricular ejection fraction (LVEF).

Ejection fraction $(\mathrm{EF})$ refers to the ratio of stroke volume to ventricular-end diastolic volume (8). This measurement is often used as a quantitative measurement of left ventricular function and is positively associated with survival in HF patients (9). Although right ventricular function is also of concern when evaluating HF patients, isolated right-sided HF is uncommon (10). Furthermore, the most common manifestation of right-sided HF is due to left-sided HF and it is recommended that these patients be managed as left-sided HF patients. In the most recent guidelines for the management of HF (2), the American College of Cardiology Foundation (ACCF)/American Heart Association (AHA), define subtypes of left-sided HF by LVEF. These subtypes include heart failure with reduced ejection fraction (HFrEF) (EF $\leq 40 \%$ ), heart failure 
with preserved ejection fraction $(\mathrm{HFpEF})(\mathrm{EF} \geq 50 \%)$ and heart failure with mid-range ejection fraction (HFmrEF) (EF 41-49\%).

This chapter includes a focused review on HF terminology as well as the two most prevalent HF subtypes, HFrEF and HFpEF. Existing literature that has investigated the relationship between high-sensitivity C-reactive protein (hs-CRP), interleukin-6 (IL-6) or soluble tumor necrosis factor- $\alpha$ receptor-1 (sTNF-R1) and HF overall, HFrEF or HFpEF are also included. It concludes with a summary of the literature and the explanation of the need for additional research.

\section{TERMINOLOGY}

Until the 1980-1990's, other than a few rare cases, HF was believed to occur exclusively in those with systolic dysfunction $(11,12)$. In fact, early drug trials in HF that sought to establish a medication that would improve adverse outcomes in this population either included only those with a reduced EF or did not differentiate by EF $(5,12)$. Over time, the repeated observation that there were individuals with signs and symptoms of HF but without overt reduced systolic dysfunction lead to the discovery of HF with diastolic dysfunction $(1,12)$. These two subtypes were accordingly named systolic heart failure (SHF) and diastolic heart failure (DHF). Although these terms seemed fitting at the time, it was soon discovered that LV systolic and LV diastolic dysfunction are not mutually exclusive with many HF patients exhibit some degree of both $(2,5$, 13). For this reason, the preferred terminology today is heart failure with reduced ejection fraction (HFrEF) and heart failure with preserved ejection fraction (HFpEF).

Terminology referring to HF overall has also changed over the years. Because pulmonary congestion has been long recognized as a cardinal sign of HF, the term congestive heart failure 
(CHF) is frequently used interchangeable with HF. Although CHF may accurately describe some HF patients, it is not always accurate as some patients present without signs or symptoms of volume overload (2). Furthermore, CHF may be misleading because this acronym is also used to refer to chronic heart failure rather than congestive heart failure (14). For these reasons, "heart failure" is the preferred terminology over "congestive heart failure" (2).

It is also of note that the 2013 ACCF/AHA Guideline for the Management of HF (2) emphasized that cardiomyopathy and LV dysfunction are not synonymous with HF. Instead, these terms should be used to describe possible reasons for the development of structural and functional abnormalities in HF.

\section{DIAGNOSIS}

Consistent with HF being termed a clinical 'syndrome' in the 1990's, no single sign, symptom, or clinical history item alone is used to diagnose HF but rather a combination of several criteria is required $(2,15)$. Currently, a national or international consensus on a set of diagnostic criteria for HF does not exist $(2,16)$. Instead, HF is often a diagnosis of exclusion following a close medical history review and physical examination (2). In light of the fact that there is not a single harmonious definition, many epidemiological, clinical, and communitybased studies have created their own criteria or used criteria produced by various organizations to diagnose HF. Commonly used criteria include the Framingham criteria (17), Gothenburg criteria (18), Boston criteria (19), and the Cardiovascular Health Study (CHS) (20) criteria, all of which rely on a combination of medical history review, signs and symptoms, radiographic evidence, and response to therapy. Overall, these criteria produce similar estimates, (21) however, they were not designed to differentiate by HFrEF and HFpEF. The Framingham 
criteria is one of the most widely used and validated of them all. It has been shown to be very sensitive (92\%) and moderately specific (79\%) for the diagnosis of HF (22). Specifically, absence of the Framingham criteria can rule out the presence of HF whereas the presence of the criteria should be used in combination with radiographic evidence, such as an echocardiography, to confirm the diagnosis. The Framingham criteria are listed in Table 1 below. A definite diagnosis requires a minimum of two major, or one major and two minor criteria present concurrently. Additionally, minor criteria cannot be attributable to any other condition.

\begin{tabular}{|c|c|}
\hline Table 1. Framingham Clinical Diagnostic Criteria for Congestive Heart Failure \\
\hline Major Criteria & Minor Criteria \\
\hline Paroxysmal nocturnal dyspnea or orthopnea & Ankle edema \\
Neck-vein distention & Night cough \\
Rales & Dyspnea on exertion \\
Cardiomegaly & Hepatomegaly \\
Acute pulmonary edema & Pleural effusion \\
S3 gallop & Vital capacity decrease $1 / 3$ from maximum \\
Increased venous pressure $\geq 16$ cm of water & Tachycardia (rate of $\geq 120$ bpm) \\
Circulation time $\geq 25$ seconds & \\
Hepatojugular reflux & Major or Minor Criterion \\
\hline \multicolumn{2}{|c|}{ Weight loss $\geq 4.5$ kg in 5 days in response to treatment* } \\
\hline \multicolumn{2}{|c|}{} \\
\hline *Serves as a major criterion if it occurred during therapeutic intervention for CHF; if due to \\
other factors it is a minor criterion.
\end{tabular}

Note. Adapted from "The Natural History of Congestive Heart Failure: the Framingham Study" by McKee et al. New England Journal of Medicine. 1971;285(26), 1441-1446.

Diagnosis by HFrEF and HFpEF is complicated by the heterogeneity of the disease processes and can be particularly difficult for $\operatorname{HFpEF}(2,5)$. Maestre et al. $(22)$ cross-matched 
HF confirmed by echocardiographic diagnostic criteria of LV dysfunction with the results obtained using the Framingham clinical diagnostic criteria for HF to see how the latter performed in ruling out SHF $(\mathrm{EF}<45 \%)$ and $\mathrm{DHF}(\mathrm{EF}>45 \%)$. The analysis revealed that the Framingham criteria can conclusively rule out the presence of SHF but not DHF (likelihood ratio for negative test result 0.04 vs. 0.10 , respectively). Other than in isolated events, systolic and diastolic LV dysfunction alone cannot accurately distinguish between HF subtypes as many individuals display characteristics of both $(2,5,13)$. However, when categorized by LVEF, distinct differences in etiology, risk profiles, and response to treatment are revealed (23). Additionally, most clinical trials and guidelines have customarily used LVEF for categorizing HFrEF and HFpEF though some might argue it is not the optimal parameter for evaluating LV systolic function $(24,25)$.

Various EF cutpoints have been used to define HFrEF and HFpEF however, the 2013 ACCF/AHA guidelines (2) for HF management defines HFrEF by an EF $\leq 40 \%$ and HFpEF by an $\mathrm{EF} \geq 50 \%$. Additionally, a third subtype that is often excluded altogether or grouped into one of the other two classes also exists. This subclass is considered heart failure with mid-range ejection fraction (HFmrEF) and it is classified as an EF ranging from $41 \%$ to 49\%. Participants with HFmrEF have been reported to most likely have primarily mild systolic dysfunction but also have features of diastolic dysfunction (5). Aside from classifying EF, the ACCF/AHA Guidelines (2) also reported several criteria that have been proposed to define HFpEF including:

1) Clinical signs or symptoms of $\mathrm{HF}$

2) Evidence of preserved or normal LVEF 
3) Evidence of abnormal left ventricular diastolic dysfunction (LVDD) that can be determined by Doppler echocardiography or cardiac catheterization

However, these proposed criteria were adapted from a 2000 study (26) in which Vasan et al. underscored the importance of distinguishing between the HF subtypes and called for the development of uniform criteria to diagnose HFpEF. Other than the brief mention of these proposed criteria, the guideline itself did not recommend any specific diagnostic criteria for HFpEF. In place, large epidemiological studies looking to define HFpEF have instead adapted previous definitions to include a LVEF cut point. Some of these key studies have been included in Table 2 below. 


\begin{tabular}{|c|c|c|c|c|}
\hline Study & Cohort & Year & LVEF & HFpEF Diagnosis \\
\hline \multirow[t]{2}{*}{ Kupari (27) } & \multirow[t]{2}{*}{$\begin{array}{l}\text { Helsinki } \\
\text { Ageing } \\
\text { Study }\end{array}$} & \multirow[t]{2}{*}{1997} & \multirow[t]{2}{*}{$\mathrm{FS} \geq 0.25$} & $\begin{array}{l}\text { At least } 3 \text { of the following (1) history of breathlessness on } \\
\text { ordinary effort; (2) audible ventricular gallop sound or HR } \\
90 \text { bpm at rest; ( } 3 \text { ) pulmonary venous congestion on CXR } \\
\text { (consensus of } 2 \text { observers) or abnormal neck vein distention } \\
\text { or palpable hepatomegaly; and (4) cardiothoracic ratio > } \\
0.55 \text { on CVR. }\end{array}$ \\
\hline & & & & FS from protocol echocardiogram at study visit \\
\hline Senni (28) & $\begin{array}{l}\text { Olmsted } \\
\text { County }\end{array}$ & 1998 & $\geq 50 \%$ & $\begin{array}{l}\text { Modified Framingham criteria. } \\
\text { LVEF from abstraction of medical record from within } 3 \mathrm{wk} \\
\text { of HF diagnosis. }\end{array}$ \\
\hline \multirow[t]{2}{*}{ Vasan (29) } & \multirow[t]{2}{*}{ FHS } & \multirow[t]{2}{*}{1999} & \multirow[t]{2}{*}{$\geq 50 \%$} & Framingham criteria \\
\hline & & & & LVEF from protocol echocardiogram at FHS study visit \\
\hline \multirow[t]{2}{*}{ Devereux (30) } & \multirow[t]{2}{*}{ SHS } & \multirow[t]{2}{*}{2000} & \multirow[t]{2}{*}{$>54 \%$} & Modified Framingham criteria \\
\hline & & & & LVEF from protocol echocardiogram at SHS study visit \\
\hline Kitzman (31) & CHS & 2001 & \multirow[t]{2}{*}{$\begin{array}{l}\text { Qualitative } \\
\text { as normal; }\end{array}$} & $\begin{array}{l}\text { Expert panel adjudication based on review of pertinent data } \\
\text { on hospitalization or outpatient visits for CHF, including } \\
\text { history, physical examination, chest x-ray reports, and } \\
\text { medication administration. Self-report of a physician } \\
\text { diagnosis of CHF was confirmed by medical record } \\
\text { documentation. }\end{array}$ \\
\hline $\begin{array}{l}\text { Gottdiener } \\
(32)\end{array}$ & CHS & 2002 & & $\begin{array}{l}\text { Qualitative assessment of systolic function from protocol } \\
\text { echocardiogram at CHD study visit }\end{array}$ \\
\hline Bursi (33) & $\begin{array}{l}\text { Olmsted } \\
\text { County }\end{array}$ & 2006 & $\geq 50 \%$ & $\begin{array}{l}\text { Framingham criteria } \\
\text { Prospective study-specific echocardiogram }\end{array}$ \\
\hline \multirow[t]{2}{*}{ Owan (34) } & \multirow[t]{2}{*}{$\begin{array}{l}\text { Mayo } \\
\text { Clinic }\end{array}$} & \multirow[t]{2}{*}{2006} & \multirow[t]{2}{*}{$\geq 50 \%$} & $\begin{array}{l}\text { ICD/DRG discharge codes (validated against Framingham } \\
\text { criteria in a subset) }\end{array}$ \\
\hline & & & & $\begin{array}{l}\text { LVEF from clinical echocardiogram performed within } 30 \\
\text { days of HF hospitalization }\end{array}$ \\
\hline Bhatia (35) & $\begin{array}{l}\text { EFFECT } \\
\text { study }\end{array}$ & 2006 & $>50 \%$ & $\begin{array}{l}\text { Framingham criteria } \\
\text { LVEF abstracted from HF hospitalization }\end{array}$ \\
\hline \multirow[t]{2}{*}{$\operatorname{Lam}(36,37)$} & \multirow[t]{2}{*}{ FHS } & \multirow[t]{2}{*}{2011} & \multirow[t]{2}{*}{$>45 \%$} & Framingham criteria \\
\hline & & & & $\begin{array}{l}\text { LVEF assessed within } 1 \mathrm{y} \text { of hospitalization (without } \\
\text { intervening event) }\end{array}$ \\
\hline \multirow[t]{2}{*}{ Gerber (38) } & $\begin{array}{l}\text { Olmsted } \\
\text { County }\end{array}$ & 2015 & $>50 \%$ & $\begin{array}{l}\text { ICD codes from hospital discharges or outpatient visits } \\
\text { (validated against Framingham criteria in a subset); }\end{array}$ \\
\hline & & & & $\begin{array}{l}\text { LVEF assessed at Mayo clinical by echocardiography w/in } \\
90 \text { days of HF diagnosis }\end{array}$ \\
\hline $\begin{array}{l}\text { CHF indicates } \\
\text { related group; } \\
\text { FS, fractional } \\
\text { ratio; ICD, imp } \\
\text { Heart Study. }\end{array}$ & IIV & ailur & HS, Cardic & $\begin{array}{l}\text { ascular Health Study; CXR, chest X-ray; DRG, diagnosis- } \\
\text { ffective Cardiac Treatment; FHS, Framingham Heart Study; } \\
\text { heart failure with preserved ejection fraction; HR, hazards } \\
\text { LVEF, left ventricular ejection fraction; and SHS, Strong }\end{array}$ \\
\hline
\end{tabular}

Note. Adapted from, "Heart Failure with Preserved Ejection Fraction in Perspective" by Pfeffer et al.

Circulation research. 2019;124(11), 1598-1617. 


\section{PATHOPHYSIOLOGY}

An estimated 17 primary etiologies of HF exist and over two-thirds can be attributed to just four underlying conditions: ischemic heart disease, chronic obstructive pulmonary disease, hypertensive heart disease, and rheumatic heart disease (39). In many cases the exact etiology of HF is unknown or related to a combination of different etiologies. Regardless, HF often manifests secondary to structural and/or functional abnormalities of the myocardium which most often result in systolic and/or diastolic dysfunction $(5,6)$. However, HF can also result from abnormalities of the pericardium, myocardium, endocardium, heart rhythm, or conduction.

Cardiac remodeling describes a progressive series of changes in the shape, size, and function of the heart (40). It is one of the most important pathophysiological processes in the development and progression of HF (41). Cardiac remodeling is often initiated by damage to the myocardium or increases in wall stress and is characterized by changes in the cardiomyocytes themselves and in the makeup of the extracellular matrix (ECM) (40). The ECM is important for maintaining the structural and functional integrity of the heart, predominately via collagen fibrils. Molecules involved in the composition or activity of the extracellular matrix that are released into circulation can be measured to detect remodeling. For example, serum concentrations of collagen fragments are positively correlated with remodeling and the development of fibrosis in the heart.

Heart failure is often considered a disease of the elderly, particularly in HFpEF (42-44).

Left ventricular wall stress can occur in response to age-related modifications of the cardiovascular system such as increased afterload, diminished chronotropic and inotropic responses, increased intracardiac pressures with ventricular filling, and impaired vasodilation $(45,46)$. Cardiac remodeling response to stress can result in hypertrophy of the cardiomyocytes 
(47). Hypertrophied cardiomyocytes demand more oxygen and energy, and failure to meet these needs can result in a hypoxic environment in which excess free radicals are produced (48). Interestingly, deficits in myocardial oxygen use in HFpEF has been correlated with hemodynamic severity (3), however, the cellular mechanisms in HFpEF specifically remain unclear (1). In response, cardiomyocytes release pro-inflammatory cytokines and chemokines in order to attract macrophages to the area (49). Macrophages are rich in matrix metalloproteinases (MMPs) which are key regulators in ECM turnover (50). Although tissue inhibitors of metalloproteinases (TIMPs) are responsible for inhibition of these proteins, with aging, levels of some TIMPs and MMPs isoforms are increased and correlate with variables of diastolic dysfunction (51). The isoform MMP-9, can process several cytokines including IL-6 and TNF- $\alpha$ and is strongly associated with increased LV stiffness and end diastolic dimension in the aging heart (50).

This describes one probable pathophysiological explanation behind cardiac remodeling and the development of HF overall in the aging heart. Although several other etiologies and resultant compensatory mechanisms exist, elucidating this disease process in older populations is important given the significant increase in prevalence and incidence in the elderly (44). Other than LV hypertrophy and stiffness, other potential compensatory mechanisms include increased cardiac output via the Frank-Starling mechanism and increased mean arterial pressure via neurohormonal systems (4).

\section{HFrEF}

As previously reported, left ventricular cardiac remodeling is one of the most important pathophysiological processes in HF (41). Four patterns of LV remodeling that have been identified include normal geometry, concentric remodeling, concentric hypertrophy and eccentric 
hypertrophy. In HFrEF, eccentric hypertrophy is the most common type of LV remodeling, however, a subset of those with HFrEF have concentric hypertrophy. The classic history of HFrEF begins with the initial damage to the myocardium, which initiates compensatory mechanisms including LV hypertrophy. Neurohormonal activation is also increased in attempt to stabilize cardiac output and contractility leading to further LV systolic dysfunction.

In a large multinational longitudinal study, Nauta et al. (41) examined differences in the pathophysiology, clinical characteristics, and response to treatment in HFrEF patients according to LV geometry. To the surprise of the investigators, a sizable portion of those with HFrEF exhibited reduced LVEF with concentric remodeling rather than eccentric remodeling. Additionally, many of those with HFrEF and concentric hypertrophy had a profile similar to HFpEF patients as they were predominately older, hypertensive women. In a sub-analysis, the investigators examined the biomarker profiles according to LV remodeling in which HFrEF patients with concentric hypertrophy were characterized by markers of oxidative stress and inflammation.

\section{HFpEF}

Patients with HFpEF comprise about half of all patients with $\operatorname{HF}(27,29,31,33,52)$, yet they frequency experience delayed diagnosis and have limited treatment options $(5,53)$. These patients are more likely to be elderly women with small, hypertrophied ventricles $(43,54)$ and several cardiovascular and non-cardiovascular comorbidities including obesity, hypertension, coronary artery disease, and metabolic syndrome $(1,54)$. The high prevalence of comorbid conditions in HFpEF may explain the cardiac changes observed in this subtype (1).

Conversely, HFpEF is characterized by the presence of left ventricular diastolic dysfunction (LVDD) (55). Evidence of LVDD is considered a preclinical condition defined as 
the inability of the LV to fill to an adequate end-diastolic volume at an acceptable pressure (56). Kane et al. (13) reported about one in four adults with moderate-severe diastolic dysfunction may develop HF. Although LVDD can occur in HFrEF just as LV systolic dysfunction can occur in HFpEF, LVDD has been reported to be the primary mechanism in HFpEF and the cause of the most unifying hemodynamic finding in HFpEF, elevated LV filling pressures $(1,55)$.

Furthermore, diastolic dysfunction has been shown to be an independent and common predictor of HFpEF and can help strengthen the diagnosis in the presence of other criteria including signs and symptoms of HF which are often nonspecific (54).

Despite the strong associations with LVDD in HFpEF it is important to also consider these patients may exhibit several other abnormalities including, but not limited to, LV systolic dysfunction, left atrial dysfunction, or long-standing pulmonary hypertension leading to right ventricular dysfunction $(1,12)$. While there has been some success elucidating several organlevel pathophysiological processes in HFpEF, the cellular mechanisms behind many of the cardiac changes observed in HFpEF are not well understood.

\section{SUMMARY}

In summary, $\mathrm{HFrEF}$ and $\mathrm{HFpEF}$ are two distinct HF subtypes. Left ventricular cardiac remodeling resulting from injury or stress, including age-related changes, is an important consideration in the development of HF. Those with HFrEF are typically characterized by eccentric LV hypertrophy whereas those with HFpEF typically exhibit concentric LV hypertrophy. Nonetheless, it is important to note that neither eccentric or concentric remodeling are unique to just HFrEF or HFpEF. 


\section{RISK FACTORS}

Traditional HF risk factors are common among the US population. Using data from the 2007-2010 National Health and Nutrition Examination Survey, Kovell et al. (57) estimated onethird of the US adult population has at least one HF risk factor. Common established risk factors for HF overall include, but are not limited to; older age, male sex, hypertension, obesity, LV hypertrophy, myocardial infarction, diabetes, smoking, metabolic syndrome, coronary artery disease, race/ethnicity, and immune activation $(2,21,23,43,56)$.

Using data from the Framingham Heart Study (FHS) original and offspring cohorts, Cardiovascular Health Study (CHS), and the Prevention of Renal and Vascular End-stage Disease study (PREVEND), Ho et al. (23) examined risk factors that were significant for HFrEF and HFpEF (Table 3). Data from these three longitudinal cohort studies were also used to examine significant differential effects of clinical covariates on HFpEF versus HFrEF (Table 4). Male sex was a significant risk factor in HFrEF only whereas age was a significantly stronger risk factor for HFpEF. Left bundle branch block and previous myocardial infarction were associated with significantly greater risk in HFrEF compared to HFpEF. Smoking status, LV hypertrophy, and left bundle branch block were also stronger risk factors in HFrEF than HFpEF. 


\begin{tabular}{|c|c|c|}
\hline Risk factors & sHR* $(95 \%$ CI $)$ & $P$ value \\
\hline \multicolumn{3}{|l|}{$\mathrm{HFpEF}$} \\
\hline Age per, 10 years & $1.90(1.74-2.07)$ & $<0.0001$ \\
\hline Male sex & $0.93(0.78-1.11)$ & 0.43 \\
\hline Systolic BP, per 20mmHg & $1.14(1.05-1.24)$ & 0.003 \\
\hline Body mass index, per $4 \mathrm{~kg} / \mathrm{m} 2$ & $1.28(1.21-1.37)$ & $<0.0001$ \\
\hline Antihypertensive treatment & $1.42(1.18-1.71)$ & 0.0002 \\
\hline Previous myocardial infarction & $1.48(1.12-1.96)$ & 0.006 \\
\hline \multicolumn{3}{|l|}{ HFrEF } \\
\hline Age, per 10 years & $1.66(1.52-1.80)$ & $<0.0001$ \\
\hline Male sex & $1.84(1.55-2.19)$ & $<0.0001$ \\
\hline Systolic BP, per 20mmHg & $1.20(1.10-1.30)$ & $<0.0001$ \\
\hline Body mass index, per $4 \mathrm{~kg} / \mathrm{m}_{2}$ & $1.19(1.11-1.28)$ & $<0.0001$ \\
\hline Antihypertensive treatment & $1.35(1.13-1.63)$ & 0.001 \\
\hline Diabetes mellitus & $1.83(1.48-2.26)$ & $<0.0001$ \\
\hline Current Smoker & $1.41(1.14-1.75)$ & 0.0015 \\
\hline Previous myocardial infarction & $2.60(2.08-3.25)$ & $<0.0001$ \\
\hline ECG LV hypertrophy & $2.12(1.55-2.90)$ & $<0.0001$ \\
\hline Left bundle branch block & $3.17(2.11-4.78)$ & $<0.0001$ \\
\hline \multicolumn{3}{|c|}{$\begin{array}{l}\mathrm{BP} \text {, blood pressure; } \mathrm{CI} \text {, confidence interval; } \mathrm{HF} \text {, heart failure; } \mathrm{HFpEF}, \mathrm{HF} \\
\text { with preserved ejection fraction; HFrEF, HF with reduced ejection fraction; } \\
\mathrm{LV} \text {, left ventricular; ECG; electrocardiogram; sHR, subdistribution hazard } \\
\text { ratio. } \\
\text { *Hazard ratio is expressed per increase in continuous variables as specified } \\
\text { in the table and for presence vs absence of dichotomous variables. }\end{array}$} \\
\hline
\end{tabular}

Note. Adapted from, "Predicting Heart Failure with Preserved and Reduced Ejection Fraction: The International Collaboration on Heart Failure Subtypes" by Ho et al. 2016. Circulation: Heart Failure, 9(6), e003116. 


\begin{tabular}{|c|c|c|c|}
\hline & $\begin{array}{c}\text { HFpEF } \\
\text { sHR* }(95 \% \text { CI })\end{array}$ & $\begin{array}{c}\text { HFrEF } \\
\text { sHR* }(95 \% \text { CI })\end{array}$ & $\begin{array}{c}p \text { for } \\
\text { equality }\end{array}$ \\
\hline Age, per 10 years & $1.91(1.78-2.06)$ & $1.69(1.59-1.81)$ & 0.02 \\
\hline Male sex & $0.91(0.79-1.05)$ & $1.87(1.63-2.16)$ & $<0.0001$ \\
\hline Systolic BP, per $20 \mathrm{mmHg}$ & $1.13(1.05-1.21)$ & $1.20(1.12-1.28)$ & 0.24 \\
\hline Body mass index, per $4 \mathrm{~kg} / \mathrm{m}_{2}$ & $1.28(1.22-1.36)$ & $1.18(1.11-1.25)$ & 0.05 \\
\hline Antihypertensive treatment & $1.41(1.21-1.65)$ & $1.33(1.14-1.54)$ & 0.59 \\
\hline Diabetes mellitus & $1.42(1.17-1.72)$ & $1.58(1.32-1.90)$ & 0.44 \\
\hline Current Smoker & $1.04(0.85-1.28)$ & $1.44(1.21-1.72)$ & 0.02 \\
\hline Previous myocardial infarction & $1.30(1.02-1.67)$ & $2.70(2.25-3.24)$ & $<0.0001$ \\
\hline ECG LV hypertrophy & $1.16(0.84-1.60)$ & $2.08(1.60-2.69)$ & 0.009 \\
\hline Left bundle branch block & $1.30(0.81-2.09)$ & $3.65(2.62-5.09)$ & 0.0008 \\
\hline \multicolumn{4}{|c|}{$\begin{array}{l}\text { *Hazard ratio is for the presence versus absence of dichotomous predictors, and per } \\
\text { increase in continuous predictors as specified in the table with all covariates shown in the } \\
\text { model simultaneously. BP indicates blood pressure; CI, confidence interval; HF, heart } \\
\text { failure; HFpEF, HF with preserved ejection fraction; HFrEF, HF with reduced ejection } \\
\text { fraction; and sHR, subdistribution hazard ratio. }\end{array}$} \\
\hline
\end{tabular}

Note. Adapted from, "Predicting Heart Failure with Preserved and Reduced Ejection Fraction: the International Collaboration on Heart Failure Subtypes" by Ho et al. 2016. Circ Heart Fail, 9(6), e003116.

Many of the original large longitudinal cohort studies in HF have historically included almost exclusively white participants including the FHS (100\% whites), PREVEND ( $96 \%$ whites), and CHS (85\% whites) (23). More recent investigations that have examined HF risk across different race/ethnicities have revealed significant risk differences $(44,58,59)$. Therefore, it is important to include a brief synopsis of some of the investigations that have examined HF in more diverse samples.

The Health, Age, and Body Composition, or Health ABC Study, examined the epidemiology of incident HF by race and gender in an elderly cohort of 2934 participants (58.6\% white, $41.4 \%$ black) without HF at baseline. The median follow-up time was 7.1 years in which $8.8 \%$ of the population developed HF. They found that men and blacks were more likely to 
develop HF, however, there were not statistically significant sex-based differences observed. Blacks had a higher overall proportion of HF attributable to modifiable risk factors compared to whites $(67.8 \%$ vs. $48.9 \%)$ with a $>5 \%$ higher population attributable risk in 6 of 8 risk factors assessed (coronary heart disease, uncontrolled blood pressure, LV hypertrophy, reduced glomerular filtration rate, smoking, and increased heart rate). Differences in survival rates after HF were not statistically significant, however, rehospitalization rates were significantly higher in blacks.

Bahrami et al. (58) examined differences in incident CHF in 6814 men and women (4584 years of age) who participated in the Multi-Ethnic Study of Atherosclerosis. This cohort included whites (38.5\%), African Americans (27.8\%), Hispanics (21.9\%) and Chinese Americans (11.8\%) who were free from cardiovascular disease at baseline. Although they did not stratify by LVEF, it was noted that $63 \%$ of the CHF participants had preserved LV function (LVEF $\geq 40 \%$ ) After a median follow-up of 4.0 years, 79 participants developed CHF. Cox proportional hazards models were used to obtain hazard ratios (HRs). African American participants had the highest incidence rate of CHF, followed by Hispanic, white, and Chinese Americans. After controlling for age, sex, hypertension, obesity, serum cholesterol level, and smoking status, analysis revealed African Americans had a significantly greater risk of CHF compared to whites (Hazard ratio [HR] 2.00; 95\% Confidence interval [CI] 1.11-3.61). However, this relationship was attenuated and no longer statistically significant after controlling for baseline LVEF determined by magnetic resonance imaging. There was not a significant association seen in the other race/ethnicities. 


\section{HEART FAILURE AND INFLAMMATION}

In 2001, the National Institutes of Health's Biomarkers Definitions Working Group defined biological markers, or biomarkers, as, "a characteristic that is objectively measured and evaluated as an indicator of normal biological processes, pathogenic processes, or pharmacologic responses to a therapeutic intervention" (60). Biomarkers can be used to help diagnose an abnormal condition, to stage the extent of a disease, to indicate disease prognosis, or to determine response to intervention.

In a 2012 review, van Kimmenade et al. (61), examined the emerging roll of biomarkers in $\mathrm{HF}$ after the clinical introduction of testing B-type natriuretic peptide (BNP) and N-terminal proBNP (NT-proBNP) in the early 2000's. Combining recommendations from various investigators and organizations, van Kimmenade et al. defined four conditions that should be met in order for the investigation of a biomarker to be useful. These conditions are as follows:

1) The methods by which a novel biomarker is judged (compared to or in combination with other biomarkers) should be thorough and evaluated across a wide range of patients that are typical of the diagnosis for which the biomarker will be applied. Additionally, the statistical methods used to evaluate the biomarker should be contemporary, rigorous, standardized and fair.

2) Measurement of a novel HF biomarker should be easily achieved within a short period of time and provide acceptable accuracy, and assays for its measurement should have defined biological variation and low analytical imprecision.

3) The biomarker should primarily reflect important (patho)physiological process(es) involved in HF presence and progression; use of a biomarker that is reflective of heart disease but originates outside of the myocardium is acceptable as long as such a 
biomarker provides independently useful information involved in the diagnosis, prognosis, progression, or therapy of HF syndromes.

4) The biomarker must provide clinically useful information for caregivers (physicians, nurses, and others) and patients to facilitate more swift and reliable establishment/rejection of a diagnosis and more accurate estimation of prognosis and to inform more successful therapeutic strategies. The information from such a biomarker should not recapitulate clinical information already available at bedside and must be additional to information provided by other biomarkers.

According to the authors, although many are close, BNP and NT-proBNP are the only biomarkers thus far that have met the above criteria. This is consistent with the 2017 Focused Update (62) of the ACCF/AHA guidelines, which recommend measuring natriuretic peptide biomarkers for the prevention, diagnosis and prognosis of HF. In addition to BNP and NTproBNP, the $2013 \mathrm{ACCF} / \mathrm{AHA}$ guidelines recommended using cardiac troponin T or I, biomarkers of myocardial injury, for evaluating HF prognosis but not for predicting new onset HF. Although other common cardiovascular biomarkers have been implicated in HF, current evidence is not enough to make these recommendations. Furthermore, considering the difficulties diagnosing HF, particularly in $\mathrm{HFpEF}$, a multi-marker strategy may be useful in establishing risk and diagnosing HF in combination with other diagnostic criteria.

So far, the natriuretic peptides, specifically BNP, have been shown to have the best predictive value in HF compared to other biomarkers (40). Although BNP is not without some limitations, one being that it can be associated with a variety of cardiac and noncardiac causes (2). Furthermore, the predictive value of BNP in HFpEF is not as well established as in HFrEF or 
HF overall. A 2012 analysis (63) examined BNP values in $159 \mathrm{HFpEF}$ (EF > 50\%) patients and found that about one-third had BNP levels below typical diagnostic thresholds. Gladden et al. (54) attributed the lower BNP values observed in HFpEF to obesity, elevated filling pressures in the early disease process, and lower wall stress secondary to concentric remodeling (64). However, other reports have distinguished that while BNP values in HFpEF are lower than in HFrEF, they are still elevated (40). According to an AHA Scientific Statement (40), there is a need for appropriate biomarkers that can properly diagnose $\mathrm{HFpEF}$ and provide pathophysiologically relevant classification. Since HF represents a complex, heterogeneous syndrome, biomarkers in HF are most commonly classified by the disease process they are involved in (61) . Candidate biomarkers involved in inflammation in HF include CRP, TNF- $\alpha$, sTNF-R1, and IL-6. Additionally, IL-6 can also be classified under the extracellular-matrix remodeling disease process.

A prospective analysis from the Health $\mathrm{ABC}$ study (65), examined the associations between CRP, IL-6 and TNF- $\alpha$ and incident HF overall, HFrEF, and HFpEF. The sample included 2610 older adults without $\mathrm{HF}$ at baseline. Following adjustment for baseline characteristics and medication, IL-6, TNF- $\alpha$, and CRP were significant predictors of incident HF overall in individuals without baseline atherosclerotic disease $(\mathrm{n}=1945)$ (Hazard ratio [HR] 1.40; 95\% Confidence interval [CI] 1.18-1.66; $p<0.001$, HR 1.40; 95\% CI 1.06-1.84; $p=0.018$, and HR $1.19 ; 95 \%$ CI $1.05-1.36 ; p=0.009$, respectively). In those with atherosclerotic disease at baseline $(\mathrm{n}=665)$, including coronary heart disease, cerebrovascular disease, or peripheral artery disease, IL-6 and TNF- $\alpha$ were significant predictors of HF risk (HR 1.23; 95\% CI 1.02-1.48; $p=$ 0.032, and HR 1.73; 95\% CI 1.26-2.38; $p=0.001$, respectively), however, CRP was not. This relationship was also examined by $\mathrm{HFrEF}(\mathrm{EF} \leq 45 \%)$ and $\mathrm{HFpEF}(\mathrm{EF}>45 \%)$. In $\mathrm{HFrEF}$, risk 
associated with elevated IL-6 was borderline significant (HR 1.21; 95\% CI 0.99-1.48; $p=0.067$ ) whereas TNF- $\alpha$ and CRP were not significant. In HFpEF, IL-6 and TNF- $\alpha$ were strongly associated with risk (HR 1.49; 95\% CI 1.19-1.86; $p<0.001$, and HR 1.81; 95\% CI 1.23-2.68, $p=$ 0.003, respectively) however, CRP was not. The weak association with CRP in this study is contradicting to other studies that have reported CRP as strong independent predictor of HF (6669). The authors attributed this finding to the rigorous controlling for confounders in their study. In some studies, the predictive value of CRP was attenuated in patients with other traditional cardiovascular risk factors present (70-72) however, this phenomenon does not seem to represent the majority.

Bozkurt et al. (73) examined the emerging role of proinflammatory cytokines, CRP, and erythrocyte sedimentation rate in patients with HF. Table 5 includes a number of investigations that have reported concentrations of various cytokine and cytokine receptors in HF. Out of all of the cytokines and cytokine receptors, TNF- $\alpha$ appears to be the most well-studied with a majority of studies reporting elevated concentrations in HF patients. According to the table, the second most well investigated cytokine is IL-6, which is also elevated in a majority of the studies. It is also evident that although fewer studies have investigated concentrations of sTNF-R1 in HF, those that have all demonstrate these concentrations are also elevated. Additionally, Table 6 shows CRP concentrations are also elevated in HF patients. 


\begin{tabular}{|c|c|c|c|c|c|c|c|c|c|c|}
\hline & \multicolumn{5}{|c|}{ Cytokines } & \multicolumn{5}{|c|}{ Cytokine receptors } \\
\hline & TNF- $\alpha$ & IL-1 & $\mathrm{IL}-2$ & IL-6 & IFN- $\gamma$ & sTNFR1 & STNFR2 & IL- 1RA & ST-2 & IL-6R \\
\hline Levine et al. [1] & + & nd & nd & nd & nd & nd & nd & nd & nd & nd \\
\hline McMurray et al. [32] & + & nd & nd & nd & nd & nd & nd & nd & nd & nd \\
\hline Dutka et al. [11] & + & nd & nd & nd & nd & nd & nd & nd & nd & nd \\
\hline Wiederman et al. [18] & + & - & nd & + & - & nd & nd & nd & nd & nd \\
\hline Katz et al. [12] & + & - & + & nd & nd & nd & nd & nd & nd & nd \\
\hline Matsumori et al. [10] & + & - & - & - & - & nd & nd & nd & nd & nd \\
\hline Ferrari et al. [19] & + & nd & nd & nd & nd & + & + & nd & nd & nd \\
\hline Torre-Amione et al. [6] & + & nd & nd & nd & nd & + & + & nd & nd & nd \\
\hline Torre-Amione et al. [5] & + & nd & nd & + & nd & nd & nd & nd & nd & nd \\
\hline Milani et al. [82] & + & nd & nd & nd & nd & + & nd & + & nd & nd \\
\hline Munger et al. [20] & - & - & nd & + & nd & nd & nd & nd & nd & $\mathrm{Nd}$ \\
\hline Testa et al. [30] & + & + & - & + & nd & nd & + & + & nd & + \\
\hline Anker et al. [83] & + & nd & nd & nd & nd & nd & nd & nd & nd & nd \\
\hline MacGowan et al. [21] & + & nd & nd & + & nd & nd & nd & nd & nd & nd \\
\hline Mohler et al. [41] & + & nd & nd & + & nd & nd & nd & nd & nd & nd \\
\hline Nishigaki et al. [84] & + & nd & nd & + & nd & nd & nd & nd & nd & nd \\
\hline Anker et al. [17] & + & nd & nd & nd & nd & + & + & nd & nd & nd \\
\hline Tsutamoto et al. [24] & + & nd & nd & + & nd & nd & nd & nd & nd & nd \\
\hline Aukrust et al. [13] & + & nd & nd & + & nd & + & + & nd & nd & - \\
\hline Dibbs et al. [25] & + & nd & nd & + & nd & nd & nd & nd & nd & - \\
\hline Rauchhaus et al. [26] & + & nd & nd & + & nd & + & + & nd & nd & nd \\
\hline Deswal et al. [34] & + & nd & nd & + & nd & + & + & nd & nd & nd \\
\hline Weinberg et al. [14] & nd & nd & nd & nd & nd & nd & nd & nd & + & nd \\
\hline \multicolumn{11}{|c|}{ nd: Not done, +: levels elevated, -: levels not elevated } \\
\hline \multicolumn{11}{|c|}{$\begin{array}{l}\text { TNF- } \alpha \text {, Tumor necrosis factor alpha, IL-1 Interleukin-1, IL-2 Interleukin-2, IL-6 Interleukin-6, IFN-c } \\
\text { interferon gamma, sTNFR1 soluble TNF receptor R1, sTNFR2 soluble TNF receptor R2, IL-1RA IL-1 }\end{array}$} \\
\hline
\end{tabular}

Adapted from, "Biomarkers of inflammation in heart failure." by Bozkurt et al. 2010. Heart failure reviews, 15(4), 331-341.

Table 6 demonstrates the associations of various biomarkers in HF and the strength of these associations (73). Concentrations of TNF- $\alpha$, IL-6, sTNF-R1, and CRP are shown to correlate with disease severity, prognosis and HF outcomes. Additionally, three of these four biomarkers with available data (TNF- $\alpha$, IL-6, and CRP) also demonstrate predictive value in the development of HF in asymptomatic patients. There was no data for this association in sTNF-R1. 


\begin{tabular}{|c|c|c|c|c|c|c|c|c|c|c|c|}
\hline & TNF- $\alpha$ & IL-6 & IL-18 & sTNF-R1 & sTNF-R2 & IL-1 RA & SST2 & IL-10 & $\begin{array}{l}\text { Chemokines } \\
\text { (MCP-1) }\end{array}$ & CRP & ESR \\
\hline $\begin{array}{l}\text { Levels are elevated in } \\
\mathrm{HF}\end{array}$ & +++ & ++ & + & ++ & ++ & + & + & + & + & ++ & ++ \\
\hline Supporting References & $\begin{array}{l}{[1,5,6,10-13,} \\
17-21,24-26, \\
30,32,34,35, \\
41, \\
82-84]\end{array}$ & {$[22,27,40]$} & [23] & {$[19,37,38]$} & {$[22,38]$} & [22] & {$[14,16]$} & [22] & [3] & {$[71,73,74]$} & {$[76,79]$} \\
\hline $\begin{array}{l}\text { Levels correlate with } \\
\text { disease severity }\end{array}$ & +++ & +++ & $\mathrm{n} / \mathrm{d}$ & ++ & ++ & + & n/d & n/d & + & ++ & n/d \\
\hline Supporting references & $\begin{array}{c}{[1,5,11,13,27,} \\
30-32,34]\end{array}$ & $\begin{array}{c}{[5,20,24,27,28,} \\
30,34,40]\end{array}$ & & {$[28,30,34,39]$} & $\begin{array}{l}{[28,30,34,} \\
39]\end{array}$ & [30] & & & [3] & {$[71,74]$} & \\
\hline $\begin{array}{l}\text { Levels correlate with } \\
\text { prognosis and HF } \\
\text { outcomes }\end{array}$ & +++ & +++ & $\mathrm{n} / \mathrm{d}$ & ++ & ++ & n/d & + & n/d & n/d & ++ & + \\
\hline Supporting references & $\begin{array}{l}{[19,24,26,34,} \\
35,41-44]\end{array}$ & {$[24,41-44]$} & & {$[26,34]$} & {$[26,34]$} & & {$[14,16,85]$} & & & {$[43,73-75]$} & {$[76,79]$} \\
\hline $\begin{array}{l}\text { Levels predict } \\
\text { development } \\
\text { of HF in } \\
\text { asymptomatic } \\
\text { patients }\end{array}$ & ++ & ++ & $\mathrm{n} / \mathrm{d}$ & $n / d$ & $\mathrm{n} / \mathrm{d}$ & n/d & & n/d & $\mathrm{n} / \mathrm{d}$ & ++ & n/d \\
\hline Supporting references & [27] & [27] & & & & & & & & [27] & \\
\hline $\begin{array}{l}\text { Levels change with } \\
\text { HF therapy }\end{array}$ & +++ & +++ & $n / d$ & ++ & ++ & $n / d$ & & ++ & $n / d$ & + & $\mathrm{n} / \mathrm{d}$ \\
\hline Supporting references & $\begin{array}{l}{[47,48,51,52,} \\
54, \\
55,57,58,86]\end{array}$ & {$[42,47,50,56]$} & & {$[22,58]$} & $\begin{array}{l}{[22,51,54,} \\
57,58]\end{array}$ & & & {$[22,52,54]$} & & {$[64,86]$} & \\
\hline \multicolumn{12}{|c|}{$\begin{array}{l}\text { TNF-a Tumor necrosis factor alpha, IL-6 Interleukin-6, IL-18 Interleukin-18, sTNFR1 soluble TNF } \\
\text { receptor R1, sTNFR2 soluble TNF receptor R2, IL-1RA IL-1 receptor antagonist, sST2 soluble ST2- } \\
\text { member of IL-1 receptor family, IL-10 Interleukin-10, MCP-1 Monocyte chemoattractant protein-1, } \\
\text { CRP C-reactive protein, ESR erythrocyte sedimentation rate, HF heart failure, n/d no data available } \\
+++ \text { Supported by large number of studies and more than one large-scale clinical trial } \\
\text { ++ supported by several number of studies and/or small-scale clinical trials and/or one large-scale } \\
\text { clinical trial } \\
\text { + supported by one small study or one small clinical trial } \\
\text { a One study suggested that elevated levels were associated with increased mortality [76], whereas the } \\
\text { other study suggested that elevated levels were associated with better prognosis [79] }\end{array}$} \\
\hline
\end{tabular}

Adapted from, "Biomarkers of inflammation in heart failure." by Bozkurt et al. 2010. Heart failure

reviews, 15(4), 331-341.

\section{SUMMARY}

In summary, the evidence suggests various cytokines, cytokine receptors, and biomarkers

of inflammation are elevated in HF patients and positively associated with HF risk. Currently, there is insufficient evidence supporting the use of these biomarkers in the diagnosis and prognosis of HF. Considering the challenges that are associated with diagnosing HF, there is an emerging need to determine the efficacy of using common biomarkers of other disease processes 
in HF. It is likely that a combination of biomarkers may provide the greatest risk stratification rather than one single biomarker. Additionally, given the distinct differences in etiology and risk factors of HFrEF and HFpEF, there is also a need to investigate this relationship by HF subtype. 


\section{REFERENCES}

1. Pfeffer MA, Shah AM, Borlaug BA. Heart failure with preserved ejection fraction in perspective. Circ Res. 2019;124(11):1598-1617.

2. Yancy CW, Jessup M, Bozkurt B, et al. 2013 ACCF/AHA guideline for the management of heart failure: executive summary: a report of the American College of Cardiology Foundation/American Heart Association Task Force on practice guidelines. Circulation. 2013;128(16):1810-52.

3. van Empel VPM, Mariani J, Borlaug BA, Kaye DM. Impaired myocardial oxygen availability contributes to abnormal exercise hemodynamics in heart failure with preserved ejection fraction. J Am Heart Assoc. 2014;3(6):e001293.

4. Kemp CD, Conte JV. The pathophysiology of heart failure. Cardiovasc Pathol. 2012;21(5):365-71.

5. Ponikowski P, Voors AA, Anker SD, et al. 2016 ESC guidelines for the diagnosis and treatment of acute and chronic heart failure: The Task Force for the diagnosis and treatment of acute and chronic heart failure of the European Society of Cardiology (ESC) developed with the special contribution of the Heart Failure Association (HFA) of the ESC. Eur J Heart Fail. 2016;18(8):891-975.

6. Heidenreich PA, Albert NM, Allen LA, et al. Forecasting the impact of heart failure in the United States: a policy statement from the American Heart Association. Circ Heart Fail. 2013;6(3):606-19.

7. Huang CH, Tsai MS, Hsieh CC, Wang TD, Chang WT, Chen WJ. Diagnostic accuracy of tissue Doppler echocardiography for patients with acute heart failure. Heart. 2006;92(12):1790-4. 
8. Robotham JL, Takata M, Berman M, Harasawa Y. Ejection fraction revisited. Anesthesiology. 1991;74(1):172-83.

9. Dunlay SM, Roger VL, Weston SA, Jiang R, Redfield MM. Longitudinal changes in ejection fraction in heart failure patients with preserved and reduced ejection fraction. Circ Heart Fail. 2012;5(6):720-6.

10. Howlett JG, McKelvie RS, Arnold JM, et al. Canadian Cardiovascular Society Consensus Conference guidelines on heart failure, update 2009: diagnosis and management of rightsided heart failure, myocarditis, device therapy and recent important clinical trials. Can J Cardiol. 2009;25(2):85-105.

11. Ferrari R, Balla C, Fucili A. Heart failure: an historical perspective. Eur Heart J Suppl. 2016;18(suppl_G):G3-10.

12. Gladden JD, Chaanine AH, Redfield MM. Heart failure with preserved ejection fraction. Annu Rev Med. 2018;69:65-79.

13. Kane GC, Karon BL, Mahoney DW, et al. Progression of left ventricular diastolic dysfunction and risk of heart failure. JAMA. 2011;306(8):856-63.

14. Bjerre M, Kistorp C, Hansen TK, et al. Complement activation, endothelial dysfunction, insulin resistance and chronic heart failure. Scand Cardiovasc J. 2010;44(5):260-6.

15. Herrmann G, Decherd GM. The chemical nature of heart failure. Ann Intern Med. $1939 ; 12(8): 1233-44$.

16. Andersson C, Vasan RS. Epidemiology of heart failure with preserved ejection fraction. Heart Fail Clin. 2014;10(3):377-88.

17. McKee PA, Castelli WP, McNamara PM, Kannel WB. The natural history of congestive heart failure: the Framingham Study. N Engl J Med. 1971;285(26):1441-6. 
18. Eriksson H, Caidahl K, Larsson B, et al. Cardiac and pulmonary causes of dyspnoeavalidation of a scoring test for clinical-epidemiological use: the Study of Men Born in 1913. Eur Heart J. 1987;8(9):1007-14.

19. Carlson KJ, Lee DC, Goroll AH, Leahy M, Johnson RA. An analysis of physicians' reasons for prescribing long-term digitalis therapy in outpatients. J Chronic Dis. 1985;38(9):733-9.

20. Schellenbaum GD, Rea TD, Heckbert SR, et al. Survival associated with two sets of diagnostic criteria for congestive heart failure. Am J Epidemiol. 2004;160(7):628-35.

21. Komanduri S, Jadhao Y, Guduru SS, Cheriyath P, Wert Y. Prevalence and risk factors of heart failure in the USA: NHANES 2013 - 2014 epidemiological follow-up study. $J$ Community Hosp Intern Med Perspect. 2017;7(1):15-20.

22. Maestre A, Gil V, Gallego J, Aznar J, Mora A, Martín-Hidalgo A. Diagnostic accuracy of clinical criteria for identifying systolic and diastolic heart failure: cross-sectional study. $J$ Eval Clin Pract. 2009;15(1):55-61.

23. Ho JE, Enserro D, Brouwers FP, et al. Predicting heart failure with preserved and reduced ejection fraction: the international collaboration on heart failure subtypes. Circ Heart Fail. 2016;9(6): e003116.

24. Henkel DM, Redfield MM, Weston SA, Gerber Y, Roger VL. Death in heart failure: a community perspective. Circ Heart Fail. 2008;1(2):91-7.

25. Andronic AA, Mihaila S, Cinteza M. Heart failure with mid-range ejection fraction - a new category of heart failure or still a gray zone. Maedica. 2016;11(4):320-4.

26. Vasan RS, Levy D. Defining diastolic heart failure: a call for standardized diagnostic criteria. Circulation. 2000;101(17):2118-21. 
27. Kupari M, Lindroos M, Iivanainen AM, Heikkilä J, Tilvis R. Congestive heart failure in old age: prevalence, mechanisms and 4-year prognosis in the Helsinki Ageing Study. J Intern Med. 1997;241(5):387-94.

28. Senni M, Tribouilloy CM, Rodeheffer RJ, et al. Congestive heart failure in the community: a study of all incident cases in Olmsted County, Minnesota, in 1991. Circulation. 1998;98(21):2282-9.

29. Vasan RS, Larson MG, Benjamin EJ, Evans JC, Reiss CK, Levy D. Congestive heart failure in subjects with normal versus reduced left ventricular ejection fraction: prevalence and mortality in a population-based cohort. J Am Coll Cardiol. 1999;33(7):1948-55.

30. Devereux RB, Roman MJ, Liu JE, et al. Congestive heart failure despite normal left ventricular systolic function in a population-based sample: the Strong Heart Study. Am J Cardiol. 2000;86(10):1090-6.

31. Kitzman DW, Gardin JM, Gottdiener JS, et al. Importance of heart failure with preserved systolic function in patients $>$ or $=65$ years of age. CHF Research Group. Cardiovascular Health Study. Am J Cardiol. 2001;87(4):413-9.

32. Gottdiener JS, McClelland RL, Marshall R, et al. Outcome of congestive heart failure in elderly persons: influence of left ventricular systolic function. The Cardiovascular Health Study. Ann Intern Med. 2002;137(8):631-639.

33. Bursi F, Weston SA, Redfield MM, et al. Systolic and diastolic heart failure in the community. JAMA. 2006;296(18):2209-16.

34. Owan TE, Redfield MM. Epidemiology of diastolic heart failure. Prog Cardiovasc Dis. $2005 ; 47(5): 320-32$. 
35. Bhatia RS, Tu JV, Lee DS, et al. Outcome of heart failure with preserved ejection fraction in a population-based study. $N$ Engl J Med. 2006;355(3):260-9.

36. Lam CS, Donal E, Kraigher-Krainer E, Vasan RS. Epidemiology and clinical course of heart failure with preserved ejection fraction. Eur J Heart Fail. 2011;13(1):18-28.

37. Lam CS, Lyass A, Kraigher-Krainer E, et al. Cardiac and non-cardiac dysfunction as precursors of heart failure with reduced and preserved ejection fraction in the community. Circulation. 2011;124(1):24-30.

38. Gerber Y, Weston SA, Redfield MM, et al. A contemporary appraisal of the heart failure epidemic in Olmsted County, Minnesota, 2000 to 2010. JAMA Intern Med. 2015;175(6):9961004.

39. Ziaeian B, Fonarow GC. Epidemiology and aetiology of heart failure. Nat Rev Cardiol. 2016;13(6):368-78.

40. Chow SL, Maisel AS, Anand I, et al. Role of biomarkers for the prevention, assessment, and management of heart failure: a scientific statement from the American Heart Association. Circulation. 2017;135(22):e1054-91.

41. Nauta JF, Hummel YM, Tromp J, et al. Concentric vs. eccentric remodeling in heart failure with reduced ejection fraction: Clinical characteristics, pathophysiology and response to treatment. Eur J Heart Fail. 2019.

42. Chioncel O, Lainscak M, Seferovic PM, et al. Epidemiology and one-year outcomes in patients with chronic heart failure and preserved, mid-range and reduced ejection fraction: an analysis of the ESC Heart Failure Long-Term Registry. Eur J Heart Fail. 2017;19(12):157485. 
43. Coats AJS. Ageing, demographics, and heart failure. Eur Heart J Suppl. 2019;21(Suppl L):L4-7.

44. Benjamin EJ, Virani SS, Callaway CW, et al. Heart disease and stroke statistics-2018 update: a report from the American Heart Association. Circulation. 2018;137(12):e67-e492.

45. Strait JB, Lakatta EG. Aging-associated cardiovascular changes and their relationship to heart failure. Heart Fail Clin. 2012;8(1):143-64.

46. Dharmarajan K, Rich MW. Epidemiology, pathophysiology, and prognosis of heart failure in older adults. Heart Fail Clin. 2007;3(4):381-7.

47. Toprak A, Reddy J, Chen W, Srinivasan S, Berenson G. Relation of pulse pressure and arterial stiffness to concentric left ventricular hypertrophy in young men (from the Bogalusa Heart Study). Am J Cardiol. 2009;103(7):978-84.

48. Wohlgemuth SE, Calvani R, Marzetti E. The interplay between autophagy and mitochondrial dysfunction in oxidative stress-induced cardiac aging and pathology. J Mol Cell Cardiol. 2014;71:62-70.

49. Chiao YA, Dai Q, Zhang J, et al. Multi-analyte profiling reveals matrix metalloproteinase-9 and monocyte chemotactic protein-1 as plasma biomarkers of cardiac aging. Circ Cardiovasc Genet. 2011;4(4):455-62.

50. Meschiari CA, Ero OK, Pan H, Finkel T, Lindsey ML. The impact of aging on cardiac extracellular matrix. Geroscience. 2017;39(1):7-18.

51. Bonnema DD, Webb CS, Pennington WR, et al. Effects of age on plasma matrix metalloproteinases (MMPs) and tissue inhibitor of metalloproteinases (TIMPs). J Card Fail. 2007;13(7):530-40. 
52. Devereux RB, Roman MJ, Liu JE, et al. Congestive heart failure despite normal left ventricular systolic function in a population-based sample: the Strong Heart Study. Am J Cardiol. 2000;86(10):1090-6.

53. Upadhya B, Kitzman DW. Heart failure with preserved ejection fraction: new approaches to diagnosis and management. Clin Cardiol. 2020;43(2):145-55.

54. Gladden JD, Linke WA, Redfield MM. Heart failure with preserved ejection fraction. Pflugers Arch. 2014;466(6):1037-53.

55. Mocan M, Mocan Hognogi LD, Anton FP, et al. Biomarkers of inflammation in left ventricular diastolic dysfunction. Dis Markers. 2019;2019:7583690-14.

56. Dunlay SM, Roger VL, Redfield MM. Epidemiology of heart failure with preserved ejection fraction. Nat Rev Cardiol. 2017;14(10):591-602.

57. Kovell LC, Juraschek SP, Russell SD. Stage A heart failure is not adequately recognized in US adults: analysis of the National Health and Nutrition Examination Surveys, 2007-2010. PloS One. 2015;10(7):e0132228.

58. Bahrami H, Kronmal R, Bluemke DA, et al. Differences in the incidence of congestive heart failure by ethnicity: the Multi-Ethnic Study of Atherosclerosis. Arch Intern Med. 2008;168(19):2138-45.

59. Thomas KL, Hernandez AF, Dai D, et al. Association of race/ethnicity with clinical risk factors, quality of care, and acute outcomes in patients hospitalized with heart failure. $\mathrm{Am}$ Heart J. 2011;161(4):746-54.

60. Biomarkers Definitions Working Group. Biomarkers and surrogate endpoints: preferred definitions and conceptual framework. Clin Pharmacol Ther. 2001;69(3):89-95. 
61. van Kimmenade RR, Januzzi JL Jr. Emerging biomarkers in heart failure. Clin Chem. 2012;58(1):127-38.

62. Yancy CW, Jessup M, Bozkurt B, et al. 2017 ACC/AHA/HFSA focused update of the 2013 ACCF/AHA guideline for the management of heart failure: a report of the American College of Cardiology/American Heart Association Task Force on Clinical Practice Guidelines and the Heart Failure Society of America. Circulation. 2017;136(6):e137-61.

63. Anjan VY, Loftus TM, Burke MA, et al. Prevalence, clinical phenotype, and outcomes associated with normal B-type natriuretic peptide levels in heart failure with preserved ejection fraction. Am J Cardiol. 2012;110(6):870-6.

64. Iwanaga Y, Nishi I, Furuichi S, et al. B-type natriuretic peptide strongly reflects diastolic wall stress in patients with chronic heart failure: Comparison between systolic and diastolic heart failure. J Am Coll Cardiol. 2006;47(4):742-8.

65. Kalogeropoulos A, Georgiopoulou V, Psaty BM, et al. Inflammatory markers and incident heart failure risk in older adults: the Health $\mathrm{ABC}$ (Health, Aging, and Body Composition) study. J Am Coll Cardiol. 2010;55(19):2129-37.

66. Bahrami H, Bluemke DA, Kronmal R, et al. Novel metabolic risk factors for incident heart failure and their relationship with obesity: the MESA (Multi-Ethnic Study of Atherosclerosis) study. J Am Coll Cardiol. 2008;51(18):1775-83.

67. Cesari M, Penninx BW, Newman AB, et al. Inflammatory markers and onset of cardiovascular events: results from the health ABC study. Circulation. 2003;108(19):231722. 
68. Vasan RS, Sullivan LM, Roubenoff R, et al. Inflammatory markers and risk of heart failure in elderly subjects without prior myocardial infarction: The Framingham Heart Study. Circulation. 2003;107(11):1486-91.

69. Cainzos-Achirica M, Miedema MD, McEvoy JW, et al. The prognostic value of high sensitivity C-reactive protein in a multi-ethnic population after more than 10 years of followup: the multi-ethnic study of atherosclerosis (MESA). Int J Cardiol. 2018;264:158-64.

70. Brouwers FP, de Boer RA, van der Harst P, et al. Incidence and epidemiology of new onset heart failure with preserved vs. reduced ejection fraction in a community-based cohort: 11year follow-up of PREVEND. Eur Heart J. 2013;34(19):1424-31.

71. Emerging Risk Factors Collaboration. C-reactive protein, fibrinogen, and cardiovascular disease prediction. $N$ Engl J Med. 2012;367(14):1310-20.

72. Buckley DI, Fu R, Freeman M, Rogers K, Helfand M. C-reactive protein as a risk factor for coronary heart disease: a systematic review and meta-analyses for the U.S. Preventive Services Task Force. Ann Intern Med. 2009;151(7):483-95.

73. Bozkurt B, Mann DL, Deswal A. Biomarkers of inflammation in heart failure. Heart Fail Rev. 2010;15(4):331-41. 
Chapter Three: Methodology 
The purpose of this prospective study was to examine the associations between elevated high-sensitivity C-reactive protein (hs-CRP), interleukin-6 (IL-6) and soluble tumor necrosis factor- $\alpha$ receptor-1 (sTNF-R1) and the risk of heart failure with reduced ejection fraction (HFrEF) and heart failure with preserved ejection fraction (HFrEF). This section provides the details of the methodology used to address the research question.

\section{DATA COLLECTION}

The Multi-Ethnic Study of Atherosclerosis (MESA) is an ongoing prospective study funded by the National Heart, Lung, and Blood Institute of the National Institutes of Health. The primary objectives of the MESA are to determine the characteristics related to the progression of subclinical cardiovascular disease (CVD) and also from subclinical to clinical CVD. Details on the MESA have been published elsewhere (1). In brief, the sample included 6,814 men and women (45-84 years of age) who were free from clinical cardiovascular disease at baseline. Participants identified as Caucasian (38\%), African American (928\%), Hispanic (22\%), or Chinese American (12\%) and were recruited from six university-affiliated field centers in the United States:

1) University of California, Los Angeles, CA

2) University of Minnesota, St. Paul, MN

3) Northwestern University, Chicago, IL

4) Wake Forest University, Winston-Salem, NC

5) John Hopkins University, Baltimore, MD

6) Columbia University, New York, NY 
Since the MESA is concerned with the natural history of subclinical and clinical CVD, participants with any known clinical disease were excluded from the sample. Additionally, participants with any incompatibility with the long-term design of the study or other components of the MESA exam were also excluded. Eligibility status was determined based off self-reported information.

The exclusion criteria were:

1. Age younger than 45 or older than 84 years

2. Physician-diagnosed:
a. Heart attack
b. Angina or taking nitroglycerin
c. Stroke or TIA
d. Heart failure

3. Current atrial fibrillation

4. Having undergone procedures related to CVD

5. Active treatment for cancer

6. Pregnancy

7. Any serious medical condition which would prevent long-term participation

8. Weight $>300$ pounds

9. Cognitive inability as judged by the interviewer

10. Living in a nursing home or on the waiting list for a nursing home

11. Plans to leave the community within five years

12. Language barrier (speaks other than English, Spanish, Cantonese or Mandarin)

13. Chest CT scan in the past year 
The baseline exam took place from July 2000-2002 and an additional four exams have been completed since 2012. Since Exam 1, participants have been contacted every 9-12 months to determine if any events of interest had occurred.

The current study was reviewed and approved by the Institutional Review Board of the University of North Florida (Appendix A). Data from the MESA was requested and obtained from the National Institutes of Health/National Heart, Lung, and Blood Institute: Biologic Specimen and Data Repository Information Coordinating Center (2).

\section{PRIMARY DEPENDENT VARIABLE}

The primary dependent variable was time to congestive heart failure (TTCHF). The variable name in the MESA is congestive heart failure (CHF) but this will be referred to as "HF" instead as it is the preferred terminology. Heart failure was an adjudicated event classified as either definite, probable, or absent. Potential HF events were primarily identified by postbaseline follow-up calls but other means of identifying events included participant notification, MESA clinic visits, National Death Index, and public obituaries. Medical records were obtained and reviewed by a panel of physicians to determine if the event met MESA criteria. Probable HF required evidence of HF symptoms, physician diagnosis of HF, and patient receiving medical treatment for HF. Definite HF required one or more additional criteria:

1) Pulmonary edema/congestion by chest $x$-ray

2) Dilated ventricle or poor left ventricular function by echocardiography or ventriculography

3) Evidence of left ventricular diastolic dysfunction 
Participants who did not meet any criteria or with just a physician diagnosis of HF without any other evidence were considered to not have HF. If the medical report specified a specific ejection fraction $(\mathrm{EF})$, the measured value was recorded. For reports that specified EF value as a range, the midpoint value rounded down to the nearest whole number was recorded. For some reports, EF was classified as either 'low' or 'normal.' Both 'probable' and 'definite' HF events were included in this analysis. Additionally, for the subtype analysis, those with an $\mathrm{EF}<50 \%$ or classified as "low" at the time of diagnosis were considered HFrEF and those with an EF $\geq 50 \%$ or classified as "normal" were considered HFpEF.

\section{PRIMARY INDEPENDENT VARIABLES}

The primary independent variables in the study included hs-CRP, IL-6, and sTNF-R1. Baseline serum samples were drawn after at least 12 hours of fasting, processed 15-30 minutes following venipuncture, and stored at either the University of Vermont or the University of Minnesota (3). All biomarkers were analyzed in the Laboratory for Clinical Biochemistry Research at the University of Vermont (Burlington, VT).

High-sensitivity C-reactive protein was measured using the BNII nephelometer (N High Sensitivity CRP; Dade Behring Inc., Deerfield, IL). This instrument utilizes a particle enhanced immunonephelometric assay to determine hs-CRP concentration. The assay range is $0.175-$ $1100 \mathrm{mg} / \mathrm{L}$. Concentrations $>10 \mathrm{mg} / \mathrm{L}$ were excluded as this is more indicative of acute infection or trauma (4). The hs-CRP variable was then dichotomized as either elevated ( $>3-10 \mathrm{mg} / \mathrm{L}$ ) or normal $(\leq 3 \mathrm{mg} / \mathrm{L})$. This range of hs-CRP concentration is classified as high risk according to the 2003 statement for healthcare professionals from the Centers for Disease Control and 
Prevention and the American Heart Association (4). Following dichotomization, the variable was log-transformed.

Interleukin-6 concentration was measured by ultra-sensitive ELISA (Quantikine HS Human IL-6 Immunoassay; R\&D Systems, Minneapolis, MN). The lower detection limit was < $0.095 \mathrm{pg} / \mathrm{mL}$ with a detection range of $0.156-10.0 \mathrm{pg} / \mathrm{mL}$. Participants were grouped by gender and 10-year age bands for categorization. The calculated outliers for each age and gender group were excluded and the remaining values were log-transformed. The 75 th percentile of the logtransformed variable for each group was considered elevated and values below the 75 th percentile were considered normal. All elevated groups were combined into one and all non-elevated groups were also combined resulting in a single dichotomized variable specific for age and gender.

The sTNF-R1 variable was measured by ultra-sensitive ELISA (Quantikine HS Human sTNF R1 Immunoassay; R\&D Systems, Minneapolis, MN). The lower detection level was 1-3 $\mathrm{pg} / \mathrm{mL}$ with a detection range of $7.8-500 \mathrm{pg} / \mathrm{mL}$. The variable was then dichotomized using the same methods as previously described in IL-6. Participants were grouped by gender and 10-year age bands for categorization. The calculated outliers for each age and gender group were excluded and the remaining values were log-transformed. The 75 th percentile of the logtransformed variable for each group was considered elevated and values below the 75 th percentile were considered normal. All elevated groups were combined into one and all non-elevated groups were also combined resulting in a single dichotomized variable specific for age and gender. 


\section{OTHER INDEPENDENT VARIABLES}

The potential confounding variables that were controlled for in this study were all measured at Exam 1, the baseline exam, and they included the following:

$A G E$

Age was self-reported on the personal history form. This was included in the analysis as a continuous variable. Additionally, age was categorized in bands of 10 for the descriptive results to demonstrate the age distribution by heart failure status in the sample.

SEX

Sex was self-reported on the personal history form as either male or female.

\section{RACE/ETHNICITY}

Race was self-reported as either Caucasian, African American, Hispanic, or Chinese.

\section{SMOKING}

Smoking status was self-reported on the personal history form and was a created variable categorized as "Current, Former, or Never." Those who answered "yes" to the question, "Have you smoked cigarettes in the past 30 days?" were considered current smokers. Those who answered "no" to having smoked cigarettes in the past 30 days but "yes" to the question, "Have you smoked at least 100 cigarettes in your lifetime?" were considered former smokers. Those who answered "no" to having smoked at least 100 cigarettes in their lifetime were considered never smokers.

\section{PHYSICAL ACTIVITY}

Physical activity (PA) was self-reported on the PA form. This was also a created variable, rather than a variable that is directly obtained as part of the MESA exam. Total intentional 
exercise was assessed based off the self-reported number of days per week and hours/minutes per day spent participating in the following activities:

1) Walking for exercise, pleasure, social reasons, walking during work breaks, or walking the dog is classified as intentional walking

2) Dancing in church, ceremonies, or for pleasure

3) Team sports such as softball, volleyball, basketball or soccer

4) Dual sports such as tennis, racketball, or paddleball

5) Individual activities such as golf, bowling, yoga, or T’ai Chi

6) Moderate effort conditioning activities such as low impact aerobics, recreational (slow) bicycling, rowing on a rowing machine or in a lake, swimming in a pool or lake, or using weight-lifting or conditioning machines at a health club.

7) Heavy effort conditioning activities such as high impact aerobics (e.g., Tai-bo, kick boxing, judo, karate), competitive or maximum effort running, bicycling, swimming, and work on health club machines.

A continuous $\mathrm{MET} \cdot \mathrm{min} / \mathrm{wk}$ variable was calculate based off participant responses. A dichotomized PA variable was then created according to the 2018 Department of Health and Human Services Physical Activity Guidelines for Americans (5). Those who reported $\geq 500$ $\mathrm{MET} \cdot \mathrm{min} / \mathrm{wk}$ were considered sufficiently active and those $<500 \mathrm{MET} \cdot \mathrm{min} / \mathrm{wk}$ were considered insufficiently active.

\section{WAIST CIRCUMFERENCE}

Waist circumference measurements $\geq 102 \mathrm{~cm}$ or $\geq 88 \mathrm{~cm}$ for men and women, respectively, were considered at risk (6). 


\section{BLOOD PRESSURE}

The last two of three blood pressure (BP) measurements were averaged for both systolic blood pressure (SBP) and diastolic blood pressure (DBP). These variables were then categorized according to the most recent blood pressure recommendations (7) as: normal $\mathrm{SBP}<120 \mathrm{mmHg}$ and DBP < 80 mmHg: elevated SBP 120-129 mmHg and DBP < $80 \mathrm{mmHg}$ : or hypertensive SBP $\geq 130 \mathrm{mmHg}$ or $\geq 80 \mathrm{mmHg}$. Additionally, participants taking any anti-hypertensive medications were classified as hypertensive as well.

\section{LOW-DENSITY LIPOPROTEIN CHOLESTEROL}

The low-density lipoprotein cholesterol (LDL-C) variable was a created variable in the MESA and was categorized according to the National Cholesterol Education Program Guidelines (NCEP) (8). Using these categorizations, LDL-C was dichotomized as $<130 \mathrm{mg} / \mathrm{dL}$ or $\geq 130$ $\mathrm{mg} / \mathrm{dL}$. Additionally, lipid-lowering medication use was self-reported on the medications form and confirmed during the medication interview. Participants taking lipid-lowering medications were also classified as having elevated LDL-C.

\section{HIGH-DENSITY LIPOPROTEIN CHOLESTEROL}

The continuous high-density lipoprotein cholesterol (HDL-C) variable was used to create a gender-stratified dichotomous variable according to the 2001 NCEP Guidelines (8), in which concentrations $<40 \mathrm{mg} / \mathrm{dL}$ for females or $<50 \mathrm{mg} / \mathrm{dL}$ for males were considered low. Additionally, participants taking lipid-lowering medications were also classified as having low HDL-C.

\section{TRIGL YCERIDES}

Triglycerides were categorized in the MESA according to the 2001 NCEP Guidelines (8). Using these categorizations, triglyceride levels were dichotomized as $<150 \mathrm{mg} / \mathrm{dL}$ or $\geq 150$ 
$\mathrm{mg} / \mathrm{dL}$. Additionally, participants taking lipid-lowering medications were also classified as having elevated triglycerides.

\section{FAMILY HISTORY OF MYOCARDIAL INFARCTION}

Family history of myocardial infarction was a created variable dichotomized (Y/N) by the self-reported history of myocardial infarction in a parents, siblings, or children.

\section{STATINS}

Statin use was reported on the medications form and confirmed during the medication interview. Using this information, the MESA created a dichotomized $(\mathrm{Y} / \mathrm{N})$ statin use variable.

\section{ORAL STEROIDS}

Oral steroid use was reported on the medications form and confirmed during the medication interview. Using this information, the MESA created a dichotomized $(\mathrm{Y} / \mathrm{N})$ oral steroid use variable.

\section{ASPIRIN}

Aspirin use was reported on the medications form and confirmed during the medication interview. Using this information, the MESA created a dichotomized $(\mathrm{Y} / \mathrm{N})$ aspirin use variable.

\section{NSAIDS (EXCLUDING ASPIRIN)}

Use of NSAIDS, excluding aspirin, was reported on the medications form and confirmed during the medication interview. Using this information, the MESA created a dichotomized (Y/N) NSAID use variable.

\section{STATISTICAL ANALYSIS}

Statistical Analysis Software 9.4 (9) was used for data management in which complex variable recodes, coding verification, and statistical analyses were performed. Descriptive 
characteristics were obtained using the means (PROC MEANS) and frequency (PROC FREQ) procedures for continuous and categorical variables, respectively. The univariate procedure (PROC UNIVARIATE) was used to calculate outliers and to determine the 75 th percentile of IL6 and sTNF-R1. SAS was also used to log-transform hs-CRP, IL-6 and sTNF-R1 to make the distributions normal or near normal.

Separate proportional hazards regression procedures (PROC PHREG) were used to calculate multivariable adjusted hazard ratios (HR) to determine risk of HF overall, HFrEF and HFpEF according to baseline hs-CRP, IL-6 and sTNF-R1 concentrations. Participants without the necessary EF data were excluded from the subtype analysis. After creating unadjusted and age-adjusted models, three additional models were made. Model 1 adjusted for demographics and behavioral covariates including age, gender, race/ethnicity, smoking, and PA. Model 2 adjusted for the variables in Model 1 plus WC, BP, HDL-C, LDL-C, triglycerides, and selfreported family history of MI. Model 3, the fully adjusted model, included Model 2 covariates plus anti-inflammatory medication use including statins, oral steroids, aspirin, and NSAIDS (excluding aspirin).

In a separate analysis using proportional hazards regression, covariates included in the fully adjusted model were chosen using a stepwise backward elimination process. For each model that was tested, potential covariates that did not contribute significantly based on $p=0.05$ were removed and excluded from subsequent analyses. A final parsimonious model was included to help elucidate the relationship between the independent and dependent variables. 


\section{REFERENCES}

1. Bild DE, Bluemke DA, Burke GL, et al. Multi-Ethnic Study of Atherosclerosis: objectives and design. Am J Epidemiol. 2002;156(9):871-81.

2. National Institutes of Health/National Health Lung and Blood Institute: Biologic Specimen and Data Repository Information Coordinating Center. In: BIOLINCC. https://biolincc.nhlbi.nih.gov/home/.

3. MESA Coordinating Center. MESA manual of operations: field center and laboratory procedures. [cited 2020 Apr 16]. Available from http://www.mesanhlbi.org/publicDocs/MesaMop/MesaMop1-5-01.doc.

4. Piercy KL, Troiano RP, Ballard, RM, et al. (2018). The physical activity guidelines for Americans. JAMA, 320(19), 2020-8.

5. Ford ES, Li C, Zhao G. (2010). Prevalence and correlates of metabolic syndrome based on a harmonious definition among adults in the US. $J$ Diabetes. 2(3), 180-93.

6. National Cholesterol Education Program (NCEP) Expert Panel on Detection, Evaluation, and Treatment of High Blood Cholesterol in Adults (Adult Treatment Panel III). JAMA. 2001;285(19):2486-97.

7. SAS Institute Inc. 2016. Base $S A S_{\circledast} 9.4$ Procedures Guide: Statistical Procedures, Sixth Edition. Cary, NC: SAS Institute Inc. 
Chapter Four: Manuscript 
BIOMARKERS OF INFLAMMATION IN HEART FAILURE PATIENTS WITH REDUCED AND PRESERVED EJECTION FRACTIONS: MULTI-ETHNIC STUDY OF ATHEROSCLEROSIS 


\begin{abstract}
Purpose: Examine the relationships between high-sensitivity C-reactive protein (hsCRP), interleukin-6 (IL-6), and soluble tumor necrosis factor- $\alpha$ receptor-1 (sTNF-R1) and the cumulative risk of heart failure with reduced (HFrEF) and preserved (HFpEF) ejection fractions in a diverse, population-based sample.
\end{abstract}

Methods: Study sample included 6,814 adult (45-84 years of age) men and women who participated in the Multi-Ethnic Study of Atherosclerosis and were free of cardiovascular disease at baseline. Cox regression was used to calculate the hazard ratios (HR) associated with elevated baseline hs-CRP (> 3-10 $\mathrm{mg} / \mathrm{L})$, IL-6 ( $>75$ th percentile) and sTNF-R1 ( $>75$ th percentile) and risk of overall HF, HFrEF (ejection fraction $[\mathrm{EF}]<50 \%$ ), and $\mathrm{HFpEF}(\mathrm{EF} \geq 50 \%)$.

Results: During $\sim 11.2$ years of follow-up there were 178 incident HF diagnoses. Elevated hs-CRP, IL-6 and sTNF-R1 were associated with a significant increased risk of HF overall (HR 1.76; 95\% Confidence interval [CI] 1.222.52, HR 1.57; 95\% 1.07-2.30, and HR 1.91; 95\% CI 1.08-3.38, respectively). Elevated hs-CRP was a significant predictor in both HFrEF and HFpEF (HR 2.05; 95\% CI 1.26-3.35, and HR 1.89; 95\% CI 1.09-3.28, respectively). Baseline IL-6 concentrations were significantly associated with increased risk of HFrEF in nonsmokers only (HR 2.33; 95\% CI 1.045.23) and of HFpEF in African Americans only (HR 5.89; 95\% CI 1.5222.80). 
Conclusion: In a diverse sample of U.S. adults, elevated hs-CRP, IL-6 and sTNF-R1 were significant predictors of HF. Furthermore, both hs-CRP and IL-6 were significant predictors in HFrEF and HFpEF. 


\section{INTRODUCTION}

Heart failure (HF) is a complex clinical syndrome in which the heart is unable to deliver the requisite amount of blood to meet metabolic demands or does so only at the cost of increased filling pressures $(1,2)$. The prevalence of HF in the general adult population ranges from 1-3\% (3-6) and increases starkly to over $10 \%$ in older populations (6-8). According to estimates from the 2011-2014 National Health and Nutrition Examination Survey, approximately 6.5 million Americans are living with HF and this is projected to increase to over 8 million by $2030(9,10)$.

Heart failure most often manifests due to structural or functional abnormalities of the left ventricle (LV) and resultant systolic or diastolic dysfunction, or a combination of the two $(1,11)$. In early investigations, HF was almost exclusively thought to be associated with reduced systolic function however, repeated observations of HF without systolic dysfunction in the late 20 th century lead to the recognition of HF with diastolic dysfunction $(2,3,12)$. These two HF subtypes were accordingly termed systolic and diastolic HF, though the preferred terminology today is heart failure with reduced ejection fraction (HFrEF) and heart failure with preserved ejection fraction (HFpEF). The change in terminology is largely due to the observation that many HF patients demonstrate some degree of both systolic and diastolic dysfunction $(11,13)$ but when classified by left ventricular ejection fraction (LVEF), HFrEF and HFpEF exhibit marked differences in etiology, risk profiles, and response to treatment (14-18). The need to differentiate between these distinct subtypes is emphasized by evidence indicating that HFpEF constitutes $\sim 50 \%$ of all HF cases (19-23). Furthermore, due to the temporal sequence of discovery, early drug trials only included those with HFrEF and medications implemented to reduce mortality in HFrEF have not been shown to be efficacious in $\operatorname{HFpEF}(3,11)$. 
Unfortunately, making this distinction can be difficult because, currently, there is not a nationally or internationally agreed upon definition, classification system, or gold standard for the clinical diagnosis of $\operatorname{HFpEF}(11,13,14)$. Despite this lack of consensus, numerous diagnostic classifications, produced by various organizations, do exist. The 2013 American College of Cardiology Foundation (ACCF)/American Heart Association (AHA) Guideline (11) for the Management of Heart Failure describes the proposed criteria to define HFpEF including; clinical signs or symptoms of HF, evidence of preserved or normal LVEF, and evidence of abnormal LV diastolic dysfunction determined by Doppler echocardiography or cardiac catheterization. Nonetheless, diagnosis of HFpEF remains difficult and primarily a diagnosis of exclusion (24, 25) A 2017 Scientific Statement from the AHA (26) highlighted the need for novel biomarkers to add meaningful diagnostic information and provide a classification relevant to the pathophysiology of HFpEF. According the 2017 Focused Update (27) of the aforementioned ACCF/AHA guidelines, there is only sufficient evidence on the efficacy of a few biomarkers, namely B-type natriuretic peptide, N-terminal pro-B-type natriuretic peptide, cardiac troponin, and some biomarkers of myocardial fibrosis, to recommend their use in the prevention, diagnosis, and prognosis of HF. Several other biomarkers in HF have been implicated but there remains a paucity of data defining their value and the need for further research, including that on biomarkers of inflammation.

Biomarkers including C-reactive protein (CRP) and pro-inflammatory cytokines interleukin-6 (IL-6) and tumor necrosis factor- $\alpha$ (TNF $\alpha$ ) have been found to be elevated in those with HF (28-31) and associated with HF onset (32-35) and prognosis (30, 36-39). One of the two soluble TNF- $\alpha$ receptors, soluble tumor necrosis factor- $\alpha$ receptor-1 (sTNF-R1), is also used as a marker of TNF- $\alpha$ activity and has been shown to be elevated in HF patients and associated 
with disease severity (40). However, few have investigated the relationship of each of these biomarkers by HF subtype $(29,37,41,42)$. The aim of this study was to investigate the association between elevated high-sensitivity CRP (hs-CRP), IL-6, and sTNF-R1 and incident HFrEF and HFpEF in a diverse sample of U.S. adults who participated in the Multi-Ethnic Study of Atherosclerosis (MESA).

\section{METHODS}

This study analyzed data from the MESA (43), a continuous, multicenter prospective cohort study sponsored by the National Heart Lung and Blood Institute of the National Institutes of Health. The primary objectives of the MESA are to 1) determine characteristics related to the progression of subclinical CVD and 2) to determine the characteristics related to the progression of subclinical to clinically overt CVD in a diverse, population-based sample. Details on the study have been published elsewhere (43). In brief, participants were recruited from six regions in the United States (US) and the final sample included 6,814 Caucasian, African American, Hispanic, and Chinese men and women (45-84 years of age) who were free of any known CVD at baseline. The first exam took place over 24 months from 2000-2002 and four additional exams have been completed since 2012. Participants were contacted for a follow-up interview every 9-12 months to determine if any new CVD conditions, hospitalizations, treatments, or changes in life habits had occurred. Additionally, information on any CVD events that occurred during follow-up was collected from participant interviews, medical records, autopsy reports, death certificates, and, in the case of out-of-hospital deaths, interviews with or questionnaires administered to physicians, relatives, or friends. Data from the MESA was requested and obtained from the National Institutes of Health/National Heart, Lung, and Blood Institute: Biologic Specimen and Data 
Repository Information Coordinating Center (44). The use of MESA data was approved by the Institutional Review Board of the University of North Florida.

Dependent Variable

The primary dependent variable was time to HF. Heart failure is an adjudicated event in which interim medical records and deaths records are abstracted and reviewed by at least two physicians. Eligible HF events are classified as either definite, probable, or absent. Since asymptomatic disease is not an endpoint of the MESA, HF classification requires the presence of HF symptoms. In addition to symptoms, classification of probable HF also requires a physician diagnosis of $\mathrm{HF}$ and evidence of the patient receiving medical treatment for HF. Classification of definite HF requires the same criteria as probable HF and one or more additional criterion such as pulmonary edema/congestion; dilated ventricle or poor LV function; or evidence of LV diastolic dysfunction. Participants with a diagnosis of HF but no other evidence are considered to not have HF. For those with verified HF events, available EF information is obtained and recorded either by the quantitative value or as 'Normal' or 'Low.' In the present study, incident HF overall included those determined to have either probable or definite HF. Participants with an $\mathrm{EF} \leq 50 \%$ or with an EF classification of 'Low' at the time of diagnosis were classified as HFrEF, and those with an EF $\geq 50 \%$ or an EF classification of 'Normal' were classified as HFpEF.

\section{Independent Variables}

The inflammatory biomarkers of interest included hs-CRP, IL-6 and sTNF-R1. Blood samples were drawn after at least 12-hours of fasting, processed 15-30 minutes following venipuncture, and stored at either the University of Vermont or the University of Minnesota (45). All biomarkers were measured in the Laboratory for Clinical Biochemistry Research at 
University of Vermont (Burlington, VT). High sensitivity CRP was measured using the BNII nephelometer (N High Sensitivity CRP; Dade Behring Inc., Deerfield, IL). This instrument utilizes a particle enhanced immunonephelometric assay to determine hs-CRP concentration. The hs-CRP variable was dichotomized as elevated $(>3-10 \mathrm{mg} / \mathrm{L})$ or normal $(<3 \mathrm{mg} / \mathrm{L})(46)$. Both IL-6 and sTNF-R1 concentrations were measured using an ultra-sensitive ELISA (Quantikine HS Human IL-6 Immunoassay and Quantikine Human STNF R1 Immunoassay; R\&D Systems, Minneapolis, MN). For both IL-6 and sTNF-R1, participants were grouped by age bands of 10 $(45-55,56-65,66-75,>75)$ and gender $(\mathrm{M} / \mathrm{F})$ and dichotomized at the 75 th percentile as either elevated or normal for each group. All elevated groups were combined into one group and all normal groups were also combined.

\section{Other Independent Variables}

Age, sex, race/ethnicity, physical activity (PA) and smoking status were self-reported at baseline on the personal history form. Age was categorized into four groups; 45-55, 56-65, 6675 , and $>75$ years of age for the descriptive results but was used as a continuous variable in the analysis. The PA variable was dichotomized using the U.S. Department of Health and Human Services (DHHS) PA guidelines (47); values $\geq 500 \mathrm{MET} \cdot \mathrm{min} / \mathrm{wk}$ were considered sufficient and those $<500 \mathrm{MET} \cdot \min /$ wk were considered insufficient. Smoking status was a calculated variable in MESA in which participants were categorized as never smokers, former smokers or current smokers. Family history of myocardial infarction (MI) was self-reported on the medical history form and included any history of MI in parents, siblings, or children. Waist circumference (WC) measurements $\geq 102 \mathrm{~cm}$ or $\geq 88 \mathrm{~cm}$ for men and women, respectively, were considered at risk. Blood pressure (BP) was categorized into three groups: systolic blood pressure $(\mathrm{SBP})<120$ $\mathrm{mmHg}$ and diastolic blood pressure (DBP) $<80 \mathrm{mmHg}$ was considered normal: SBP 120-129 
$\mathrm{mmHg}$ and $\mathrm{DBP}<80 \mathrm{mmHg}$ elevated: and $\mathrm{SBP}>130 \mathrm{mmHg}$ or DBP $\geq 80 \mathrm{mmHg}$ hypertensive. Participants who reported anti-hypertensive medication use were also considered hypertensive. Using the National Cholesterol Education Program Guidelines (48), triglyceride values $\geq 150$ $\mathrm{mg} / \mathrm{dL}$ and low-density lipoprotein values $\geq 130 \mathrm{mg} / \mathrm{dL}$ were considered elevated. High-density lipoprotein levels $<40 \mathrm{mg} / \mathrm{dL}$ for females or $<50 \mathrm{mg} / \mathrm{dL}$ for males were considered low. Participants who reported lipid-lowering medication use were also considered to have elevated lipid levels. All self-reported medication use was confirmed during a medication use interview. Anti-inflammatory medications included; oral steroids $(\mathrm{Y} / \mathrm{N})$, statins $(\mathrm{Y} / \mathrm{N})$, aspirin $(\mathrm{Y} / \mathrm{N})$, and non-steroidal anti-inflammatory agents (excluding aspirin) (Y/N).

\section{STATISTICAL ANALYSIS}

Data was managed using SAS version 9.4 (SAS Institute, Cary, NC) (49). SAS was used for variable recoding, coding verification, and statistical analyses. Descriptive characteristics were obtained using the means and frequency procedures for continuous and categorical variables, respectively. The univariate procedure was used to calculate outliers and to determine the 75th percentile of IL-6 and sTNF-R1. SAS was used to log-transform hs-CRP following dichotomization and IL-6 and sTNF-R1 prior to classification. Separate proportional hazards regression models were used to calculate multivariable adjusted hazard ratios (HRs) to determine risk of HF overall, HFrEF, and HFpEF in those with elevated hs-CRP, IL-6 and sTNF-R1 concentrations at baseline. The level of significance was set at $\alpha=0.05$ for all tests. Heart failure participants without EF data were excluded from the subtype analyses.

After creating unadjusted and age-adjusted models, three additional models were made.

Model 1 adjusted for demographics and behavioral covariates including age, gender, 
race/ethnicity, smoking, and PA. Model 2 adjusted for the variables in Model 1 plus WC, BP, HDL, LDL, triglycerides, and self-reported family history of MI. Model 3, the fully adjusted model, included Model 2 covariates plus anti-inflammatory medication use including statins, oral steroids, aspirin, and NSAIDS (excluding aspirin).

In a separate analysis using proportional hazards regression, covariates included in the fully adjusted model were chosen using a stepwise backward elimination process. For each model that was tested, potential covariates that did not contribute significantly based on $p=0.05$ were removed and excluded from subsequent analyses. A final parsimonious model was included to help elucidate the relationship between the independent and dependent variables.

\section{RESULTS}

During $\sim 11.2$ years of follow-up, 178 adults developed HF. Of these participants, 158 had the appropriate EF data for the subtype analysis, resulting in 87 categorized as HFrEF (55.1\%) and 71 categorized as HFpEF (44.9\%). Table 1 illustrates sample characteristics according to HF status and subtype. 
Table 1. Baseline Characteristics of U.S. Adults by HF Status

\begin{tabular}{|c|c|c|c|c|}
\hline Total $(\mathrm{N}=6,814)$ & $\begin{array}{l}\text { Total HF } \\
\text { N (\%) }\end{array}$ & $\begin{array}{l}\text { HFrEF } \\
\mathrm{N}(\%)\end{array}$ & $\begin{array}{l}\text { HFpEF } \\
\text { N (\%) }\end{array}$ & $\begin{array}{l}\text { No HF } \\
\text { N }(\%)\end{array}$ \\
\hline Total N & $178(2.61)$ & $87(1.28)$ & $71(1.05)$ & $6,636(97.39)$ \\
\hline Age, Mean (SD) & $68.9(8.72)$ & $67.7(8.99)$ & $70.1(8.31)$ & $61.9(10.20)$ \\
\hline \multicolumn{5}{|l|}{ Age Categories } \\
\hline $45-55$ & $16(8.99)$ & $9(10.34)$ & $6(8.45)$ & $2130(32.10)$ \\
\hline $56-65$ & $43(24.16)$ & $24(27.59)$ & $14(19.72)$ & $1895(28.56)$ \\
\hline $66-75$ & $71(39.89)$ & $32(36.78)$ & $30(42.25)$ & $1853(27.92)$ \\
\hline$>75$ & 48 (26.97) & $22(25.29)$ & $21(29.58)$ & 758 (11.42) \\
\hline \multicolumn{5}{|l|}{ Gender } \\
\hline Male & $106(59.55)$ & $61(70.11)$ & $36(50.70)$ & 3107 (46.82) \\
\hline Female & $72(40.45)$ & $26(29.89)$ & $35(49.30)$ & $3529(53.18)$ \\
\hline \multicolumn{5}{|l|}{ Race/Ethnicity } \\
\hline Caucasian & $69(38.76)$ & $33(37.93)$ & $29(40.85)$ & 2554 (38.49) \\
\hline African American & $61(34.27)$ & $35(40.23)$ & $20(28.17)$ & $1830(27.58)$ \\
\hline Hispanic & $38(21.35)$ & $17(19.54)$ & $15(21.13)$ & $1458(21.97)$ \\
\hline Chinese & $10(5.62)$ & $2(2.30)$ & $7(9.86)$ & $794(11.97)$ \\
\hline \multicolumn{5}{|l|}{ Smoking Status } \\
\hline Never & $72(40.68)$ & $35(40.70)$ & $28(40.00)$ & $3346(50.58)$ \\
\hline Former & $77(43.50)$ & $33(38.37)$ & $37(52.11)$ & $2410(36.43)$ \\
\hline Current & $28(15.82)$ & $18(20.93)$ & $8(11.27)$ & $859(12.99)$ \\
\hline \multicolumn{5}{|l|}{ Physical Activity Level } \\
\hline$\geq 500 \mathrm{MET}-\mathrm{min} / \mathrm{wk}$ & $93(52.25)$ & $45(51.72)$ & $39(54.93)$ & 4079 (61.47) \\
\hline$<500 \mathrm{MET}-\mathrm{min} / \mathrm{wk}$ & $85(47.75)$ & $42(48.28)$ & $32(45.07)$ & $2557(38.53)$ \\
\hline \multicolumn{5}{|l|}{ Waist Circumference (cm) } \\
\hline$<102, \mathrm{M} ;<88 \mathrm{~W}$ & $59(33.15)$ & $33(37.93)$ & $20(28.17)$ & $3032(45.69)$ \\
\hline$\geq 102, \mathrm{M} ; \geq 88 \mathrm{~W}$ & $119(66.85)$ & $54(62.07)$ & $51(71.83)$ & $3604(54.31)$ \\
\hline \multicolumn{5}{|l|}{ Blood Pressure } \\
\hline Normal & $16(8.99)$ & $9(10.34)$ & $5(7.04)$ & $2191(33.03)$ \\
\hline Elevated & $10(5.62)$ & $3(3.45)$ & $6(8.45)$ & $532(8.02)$ \\
\hline Hypertensive & $152(85.39)$ & $75(86.21)$ & $60(84.51)$ & $3911(58.95)$ \\
\hline \multicolumn{5}{|l|}{ Family history of MI } \\
\hline No & $84(52.83)$ & $34(43.59)$ & $41(65.08)$ & $3577(57.36)$ \\
\hline Yes & $75(47.17)$ & $44(56.41)$ & $22(34.92)$ & $2659(42.64)$ \\
\hline \multicolumn{5}{|l|}{ Total Cholesterol (mg/dL) } \\
\hline LDL-C $\geq 130$ & $75(43.10)$ & $37(43.53)$ & $28(40.00)$ & 3009 (45.92) \\
\hline $\mathrm{TG} \geq 150$ & $87(48.88)$ & $41(47.13)$ & $35(49.30)$ & $2642(39.95)$ \\
\hline HDL-C $<40, \mathrm{M} ;<50 \mathrm{~W}$ & $96(53.93)$ & $52(59.77)$ & $34(47.89)$ & $3082(46.46)$ \\
\hline \multicolumn{5}{|l|}{ hs-CRP } \\
\hline Normal & $86(56.58)$ & $42(53.85)$ & $35(59.32)$ & $4235(70.12)$ \\
\hline Elevated & $66(43.42)$ & $36(46.15)$ & $24(40.68)$ & $1805(29.88)$ \\
\hline \multicolumn{5}{|l|}{ IL-6 } \\
\hline Normal & $87(63.04)$ & $47(64.38)$ & $31(60.78)$ & $4328(75.31)$ \\
\hline Elevated & $51(36.96)$ & $26(35.62)$ & $20(39.22)$ & 1419 (24.69) \\
\hline \multicolumn{5}{|l|}{ sTNF-R1 } \\
\hline Normal & 35 (59.32) & $15(60.00)$ & $15(60.00)$ & $1900(75.31)$ \\
\hline Elevated & $24(40.68)$ & $10(40.00)$ & $10(40.00)$ & $623(24.69)$ \\
\hline \multicolumn{5}{|l|}{ Medications } \\
\hline Statins & $32(17.98)$ & $17(19.54)$ & $11(15.49)$ & $977(14.73)$ \\
\hline
\end{tabular}


Oral Steroids

Aspirin

NSAIDs (excluding aspirin)
7 (3.93)

$63(35.39)$

$31(17.42)$

$$
5 \text { (5.75) }
$$

$21(24.14)$

$$
2 \text { (2.82) }
$$

$9(12.68)$
98 (1.48)

$1639(24.71)$

$1158(17.46)$

$\mathrm{HF}$, heart failure; HFrEF, heart failure reduced ejection fraction (EF $\leq 50$ or "Low"); HFpEF, heart failure preserved ejection fraction (EF $>50$ or "Normal"); MI, myocardial infarction; hs-CRP, high sensitivity C-reactive protein (> 3-10 mg/L); IL-6, interleukin-6 ( 75 th percentile); sTNF-R1, tumor necrosis factor- $\alpha$ receptor-1 (75 th percentile); NSAID, non-steroidal anti-inflammatory drug; M; men, W; women. Blood pressure (mmHg): Normal; SBP $<120$ and DBP < 80, Elevated; SBP 120129 and DBP $<80$, Hypertensive; SBP $\geq 130$ or DBP $\geq 80$; LDL-C, low-density lipoprotein; HDL-C high-density lipoprotein; TG, triglyceride.

The prevalence of HF overall in the sample was $2.6 \%$ (1.5\% of men and $1.0 \%$ of women, $p=0.01)$. On average, those with HF were significantly older than those without HF, regardless of subtype. There was a significantly greater proportion of males than females in HF overall $(p=$ $0.01)$ and in HFrEF $(p<0.001)$, however, the same was not true for those with HFpEF ( $p=$ 0.90). There was a greater proportion of African Americans with HFrEF and a greater proportion of Caucasians in HFpEF. 
Table 2. HRs for Incident HF, HFrEF, and HFpEF in U.S. Adults with Elevated Inflammatory Biomarkers

\begin{tabular}{|c|c|c|c|c|c|c|}
\hline \multicolumn{7}{|c|}{ HF Overall } \\
\hline & \multicolumn{2}{|c|}{ hs-CRP } & \multicolumn{2}{|c|}{ IL-6 } & \multicolumn{2}{|c|}{ sTNF-R1 } \\
\hline & HR & $95 \% \mathrm{CI}$ & $\mathrm{HR}$ & $95 \% \mathrm{CI}$ & $\mathrm{HR}$ & $95 \% \mathrm{CI}$ \\
\hline Unadjusted & $1.80^{* * *}$ & $1.31-2.49$ & $1.83 * * *$ & $1.29-2.58$ & $2.12 * *$ & $1.26-3.57$ \\
\hline Age adjusted & $1.86^{* * *}$ & $1.35-2.57$ & $1.81 * * *$ & $1.28-2.56$ & $2.08 * *$ & $1.24-3.50$ \\
\hline Model 1 & $1.85^{* * *}$ & $1.32-2.58$ & $1.66^{* *}$ & $1.16-2.36$ & $1.88^{*}$ & $1.04-3.20$ \\
\hline Model 2 & $1.77 * *$ & $1.23-2.54$ & $1.56^{*}$ & $1.06-2.29$ & 1.72 & $0.95-3.12$ \\
\hline Model 3 & $1.73 * *$ & $1.20-2.50$ & $1.50^{*}$ & $1.02-2.22$ & 1.64 & $0.93-3.06$ \\
\hline \multicolumn{7}{|c|}{ HFrEF } \\
\hline & \multicolumn{2}{|c|}{ hs-CRP } & \multicolumn{2}{|c|}{ IL-6 } & \multicolumn{2}{|c|}{ sTNF-R1 } \\
\hline & $\mathrm{HR}$ & $95 \% \mathrm{CI}$ & $\mathrm{HR}$ & $95 \% \mathrm{CI}$ & $\mathrm{HR}$ & $95 \% \mathrm{CI}$ \\
\hline Unadjusted & $2.02 * * *$ & $1.29-3.16$ & $1.73^{*}$ & $1.07-2.80$ & 2.07 & $0.93-4.61$ \\
\hline Age adjusted & $2.06^{* * *}$ & $1.32-3.22$ & $1.72 *$ & $1.07-2.78$ & 2.04 & $0.92-4.56$ \\
\hline Model 1 & $2.05^{* *}$ & $1.29-3.26$ & 1.49 & $0.91-2.44$ & 1.68 & $0.73-3.88$ \\
\hline Model 2 & $1.94 * *$ & $1.17-3.22$ & 1.47 & $0.86-2.51$ & 1.77 & $0.70-4.44$ \\
\hline Model 3 & $1.90 * *$ & $1.14-3.15$ & 1.39 & $0.81-2.38$ & 1.69 & $0.67-4.24$ \\
\hline \multicolumn{7}{|c|}{ HFpEF } \\
\hline & \multicolumn{2}{|c|}{ hs-CRP } & \multicolumn{2}{|c|}{ IL-6 } & \multicolumn{2}{|c|}{ sTNF-R1 } \\
\hline & $\mathrm{HR}$ & $95 \% \mathrm{CI}$ & $\mathrm{HR}$ & $95 \% \mathrm{CI}$ & $\mathrm{HR}$ & $95 \%$ CI \\
\hline Unadjusted & 1.62 & $0.96-2.73$ & $2.02 * *$ & $1.15-3.55$ & 2.08 & $0.93-4.64$ \\
\hline Age adjusted & $1.72 *$ & $1.02-2.90$ & $2.01 * *$ & $1.14-3.53$ & 2.07 & $0.93-4.61$ \\
\hline Model 1 & $1.79^{*}$ & 1.04-3.09 & $2.02 * *$ & $1.14-3.59$ & 2.02 & $0.90-4.55$ \\
\hline Model 2 & 1.77 & $0.98-3.18$ & 1.70 & $0.91-3.17$ & 1.89 & $0.78-4.59$ \\
\hline Model 3 & 1.76 & $0.97-3.18$ & 1.69 & $0.90-3.16$ & 1.96 & $0.81-4.75$ \\
\hline
\end{tabular}

$\mathrm{HF}$, heart failure; HFrEF, heart failure with reduced ejection fraction (EF $<50$ or "Low"); HFpEF, heart failure with preserved ejection fraction ( $\mathrm{EF} \geq 50$ or "Normal"); hs-CRP, high-sensitivity Creactive protein (> 3-10 mg/L); IL-6, interleukin-6 (75 th percentile); sTNF-R1, soluble tumor necrosis factor- $\alpha$ receptor-1 (75th percentile); HR, hazard ratio; CI, confidence interval.

${ }^{*} p<0.05 ; * * p \leq 0.01 ; * * * p \leq 0.001$

Model 1: Adjusted for age, gender, race/ethnicity, smoking, physical activity; Model 2: Model $1+$ waist circumference, blood pressure, HDL-C, LDL-C, triglycerides, family history of myocardial infarction; Model 3: Model $2+$ statins, oral steroids, aspirin, NSAIDs (excluding aspirin)

\section{Risk of $H F$}

Table 2 displays the multivariable adjusted HR obtained using the proportional hazards regression procedure for $\mathrm{HF}$ overall, $\mathrm{HFrEF}$, and $\mathrm{HFpEF}$. In the fully adjusted model, participants with elevated hs-CRP had a significantly greater risk of HF overall (HR 1.73; 95\% Confidence Interval [CI] $1.20-2.50 ; p \leq 0.01$ ). In those with elevated IL-6, the risk of HF overall 
was attenuated after controlling for covariates but remained statistically significant in the in the fully adjusted model (HR 1.50; 95\% CI 1.02-2.22; $p<0.05)$. In the age-adjusted model, adults with elevated sTNF-R1 concentrations had a significantly greater risk of HF overall however, after adjusting for anti-inflammatory medications, this relationship was borderline significant $(p$ $=0.06)$.

Table 3 includes the HRs of HF overall in the parsimonious models. In this analysis, elevated hs-CRP, IL-6 and sTNF-R1 were all significantly associated with an increased risk of HF overall with the greatest risk seen in elevated sTNF-R1 (HR 1.91; 95\% CI 1.08-3.38; $p<$ 0.05). Females had a significantly lower risk of HF compared to males with the lowest risk seen in the hs-CRP model (HR 0.43; 95\% CI 0.29-0.64; $p \leq 0.001$ ). Self-reported smokers had a twotime greater risk of HF whereas those who were hypertensive at baseline showed a three to fourtime greater risk of HF in all three models. Overall, the significant contributors seen across all three models were the same apart from PA in IL-6, and WC and oral steroids in sTNF-R1, which did not significantly contribute to either model. 
Table 3. HRs for Incident HF in U.S. Adults with Elevated Inflammatory Markers

\begin{tabular}{|c|c|c|c|c|c|c|}
\hline & \multicolumn{2}{|r|}{ hs-CRP } & \multicolumn{2}{|r|}{ IL-6 } & \multicolumn{2}{|c|}{ sTNF-R1 } \\
\hline & HR & $95 \% \mathrm{CI}$ & HR & $95 \% \mathrm{CI}$ & HR & $95 \% \mathrm{CI}$ \\
\hline Biomarker & & & & & & \\
\hline Elevated & 1.76 & $1.22-2.52 * *$ & 1.57 & $1.07-2.30 *$ & 1.91 & $1.08-3.38 *$ \\
\hline Age & 1.07 & $1.04-1.09 * * *$ & 1.07 & $1.04-1.09 * * *$ & 1.09 & $1.06-1.13 * * *$ \\
\hline Gender & & & & & & \\
\hline Male & & & & & & \\
\hline $\begin{array}{c}\text { Female } \\
\text { Smoking Status }\end{array}$ & 0.43 & $0.29-0.64 * * *$ & 0.47 & $0.31-0.70^{* * *}$ & 0.54 & $0.30-0.99 *$ \\
\hline Never & & & & & & \\
\hline Former & 1.07 & $0.72-1.58$ & 1.21 & $0.81-1.82$ & 0.99 & $0.52-1.91$ \\
\hline Current & 2.24 & $1.35-3.70^{* *}$ & 2.50 & $1.45-4.33 * * *$ & 2.92 & $1.30-6.57 * *$ \\
\hline Blood Pressure & & & & & & \\
\hline Normal & & & & & & \\
\hline Elevated & 1.50 & $0.56-4.01$ & 2.22 & $0.76-6.42$ & 2.90 & $0.71-11.77$ \\
\hline $\begin{array}{c}\text { Hypertensive } \\
\text { Physical Activity Level }\end{array}$ & 3.16 & $1.71-5.83 * *$ & 4.35 & $2.08-9.09^{* * *}$ & 4.03 & $1.41-11.51 * *$ \\
\hline $\begin{array}{l}\text { Physical Activity Level } \\
\geq 500 \text { MET-min/wk }\end{array}$ & & & & & & \\
\hline$<500 \mathrm{MET}-\mathrm{min} / \mathrm{wk}$ & 1.44 & $1.01-2.04 *$ & & & 1.96 & $1.19-3.45 * *$ \\
\hline Waist Circumference $(\mathrm{cm})$ & & & & & & \\
\hline$<102, \mathrm{M} ;<88 \mathrm{~W}$ & & & & & & \\
\hline $\begin{array}{l}\quad \geq 102, \mathrm{M} ; \geq 88 \mathrm{~W} \\
\text { Medications }\end{array}$ & 1.54 & $1.05-2.28^{*}$ & 1.62 & $1.08-2.43^{* *}$ & & \\
\hline Oral Steroids & 2.50 & $1.09-5.73 *$ & 3.33 & $1.45-7.63 * *$ & & \\
\hline
\end{tabular}

$\mathrm{HF}$, heart failure; hs-CRP, high sensitivity C-reactive protein (> 3-10 mg/L); IL-6, interleukin-6 (75th percentile); sTNF-R1, soluble tumor necrosis factor- $\alpha$ receptor-1 (75th percentile); HR, hazard ratio; CI, confidence interval; $\mathrm{M}$; men, $\mathrm{W}$; women. Blood pressure (mmHg): Normal; $\mathrm{SBP}<120$ and $\mathrm{DBP}<80$, Elevated; SBP $120-129$ and $\mathrm{DBP}<80$, Hypertensive; SBP $\geq 130$ or DBP $\geq 80 . * p<0.05 ; * * p \leq 0.01 ; * * * p \leq 0.001$

\section{Risk of HFrEF}

In the fully adjusted model, participants with elevated hs-CRP had a significant increased risk of HFrEF (HR 1.90; 95\% CI 1.14-3.15; $p \leq 0.01$ ) (Table 2). For those with elevated baseline IL-6 concentrations, the age-adjusted model revealed a significant $72 \%$ increased risk of HFrEF (HR 1.72; 95\% CI 1.07-2.78; $p<0.05$ ), however, this relationship did not remain statistically significant in the fully adjusted model. Elevated sTNF-R1 was not significantly associated with risk of HFrEF in any model. 
Table 4 includes the HRs of HFrEF in the parsimonious models. Elevated hs-CRP was associated with a significant two-time greater risk of HFrEF (HR 2.05; 95\% CI 1.26-3.35; $p \leq$ 0.01). For IL-6, when the smoking status variable was added to the model the relationship was attenuated and longer statistically significant, so the model was stratified by never smokers and current or former smokers. This revealed that for smokers or former smokers, IL-6 did not significantly contribute to the model, however, for never smokers it did (HR 1.71; 95\% CI 0.883.32; $p>0.05$, and HR 2.33; 95\% CI 1.04-5.23; $p<0.05$, respectively). Elevated sTNF-R1 was not significantly associated with risk of HFrEF in any model (data not shown).

Table 4. HRs for Incident HFrEF in U.S. Adults with Elevated Inflammatory Markers

\begin{tabular}{|c|c|c|c|c|c|c|}
\hline & \multirow{2}{*}{\multicolumn{2}{|c|}{ hs-CRP }} & \multicolumn{4}{|c|}{ IL-6 } \\
\hline & & & \multicolumn{2}{|c|}{ Never Smokers } & \multicolumn{2}{|c|}{ Ever Smokers } \\
\hline & HR & $95 \% \mathrm{CI}$ & HR & $95 \% \mathrm{CI}$ & HR & $95 \% \mathrm{CI}$ \\
\hline Biomarker & & & & & & \\
\hline Elevated & 2.05 & $1.26-3.35 * *$ & 2.33 & $1.04-5.23 *$ & 1.71 & $0.88-3.32$ \\
\hline Age & 1.04 & $1.02-1.07 * * *$ & 1.06 & $1.02-1.10 * *$ & 1.05 & $1.01-1.09 * *$ \\
\hline Gender & & & & & & \\
\hline Male & & & & & & \\
\hline Female & 0.28 & $0.16-0.49 * * *$ & 0.29 & $0.12-0.67 * *$ & 0.25 & $0.10-0.61 * *$ \\
\hline Medications & & & & & & \\
\hline Oral Steroids & 4.80 & $1.91-12.06 * * *$ & 8.81 & $1.99-38.98 * *$ & & \\
\hline Smoking Status & & & & & & \\
\hline Never & & & & & & \\
\hline Former & 0.91 & $0.52-1.60$ & & & & \\
\hline Current & 2.71 & $1.43-5.13 * *$ & & & & \\
\hline Family hx & & & & & & \\
\hline No & & & & & & \\
\hline Yes & 1.89 & $1.16-3.07 * *$ & & & & \\
\hline Blood Pressure & & & & & & \\
\hline Normal & & & & & & \\
\hline Elevated & 0.88 & $0.18-4.28$ & & & & \\
\hline Hypertensive & 3.38 & $1.51-7.55^{* *}$ & & & & \\
\hline
\end{tabular}

HFrEF, heart failure with reduced ejection fraction (EF $<50$ or "Low"); hs-CRP, highsensitivity C-reactive protein (>3-10 mg/L); IL-6, interleukin-6 (75th percentile); HR, hazard ratio; CI, confidence interval; M; men, W; women. Blood pressure (mmHg): Normal; SBP < 120 and DBP $<80$, Elevated; SBP 120-129 and DBP $<80$, Hypertensive; SBP $\geq 130$ or DBP $\geq 80$. ${ }^{*} p<0.05 ; * * p \leq 0.01 ; * * * p \leq 0.001$ 


\section{Risk of HFpEF}

Those with elevated hs-CRP had a borderline $76 \%$ increased risk of HFpEF in the fully adjusted model (HR 1.76; 95\% CI 0.97-3.18; $p=0.06)$. In IL-6 the age-adjusted model revealed a significant increased risk of HFpEF (HR 2.05; 95\% CI 1.17-3.60; $p=0.01$ ), however, after adjusting for WC this relationship did not remain statistically significant. Elevated sTNF-R1 was not significantly associated with risk of HFpEF in any model.

Table 5 includes the HRs of HFpEF in the parsimonious models. Elevated hs-CRP was associated with a significant $89 \%$ increased risk of HFpEF and nearly a five-times greater risk in hypertensive individuals compared to their normotensive counterparts. For IL-6, when the race/ethnicity variable was added to the model, the relationship was no longer significant, so the model was stratified by race/ethnicity. This revealed that African Americans with elevated IL-6 had almost a six-time significantly greater risk of HFpEF (HR 5.89; 95\% CI 1.52-22.80; $p \leq$ 0.01). There was not a significant relationship seen with elevated IL-6 in Caucasians, Hispanics, or Chinese Americans (data not shown). Elevated sTNF-R1 was not significantly associated with risk of HFrEF in any model (data not shown). 
Table 5. HRs for Incident HFpEF in U.S. Adults with Elevated Inflammatory Markers

\begin{tabular}{l|ll|ll}
\hline \multicolumn{2}{c}{} & \multicolumn{2}{c}{ hs-CRP } & \multicolumn{2}{c}{ IL-6 } \\
& HR & $95 \%$ CI & HR & 95\% CI \\
\hline $\begin{array}{l}\text { Inflammatory Biomarker } \\
\quad \text { Elevated }\end{array}$ & 1.89 & $1.09-3.28^{*}$ & 5.89 & $1.52-22.80^{* *}$ \\
Age & 1.09 & $1.05-1.13^{* * *}$ & 1.09 & $1.02-1.17^{* *}$ \\
Blood Pressure & & & & \\
$\quad \begin{array}{llll}\text { Normal } \\
\text { Elevated } \\
\quad \text { Hypertensive }\end{array}$ & & & & \\
\hline
\end{tabular}

HFpEF, heart failure with preserved ejection fraction (EF $\geq 50$ or "Normal"); hs-CRP, high-sensitivity C-reactive protein ( $>3-10 \mathrm{mg} / \mathrm{L})$; IL-6, interleukin-6 (75th percentile); HR, hazard ratio; CI, confidence interval. Normal; SBP < 120 and DBP $<80$, Elevated; SBP 120-129 and DBP $<80$, Hypertensive; $\mathrm{SBP} \geq 130$ or DBP $\geq 80 * p<0.05 ; * * p \leq 0.01 ; * * * p \leq 0.001$

\section{DISCUSSION}

Recent reports $(11,26,50)$ have addressed the need for investigating the novel use of biomarkers in the evaluation and management of HF patients. In this multi-ethnic, populationbased sample, elevated hs-CRP ( $>3-10 \mathrm{mg} / \mathrm{L})$, IL-6 ( $>75$ th percentile) and sTNF-R1 $(>75$ th percentile) were associated with a significant increase in risk of HF. When examining risk by HF subtype, hs-CRP was a significant predictor in both HFrEF and HFpEF. Interestingly, baseline IL-6 concentrations were a significant predictor of HFrEF in nonsmokers only and of HFpEF in African Americans only. These findings add to the evidence demonstrating a positive relationship between biomarkers of inflammation in $\operatorname{HF}(32,35,51)$ and to the risk differences seen in HFrEF and HFpEF (17).

Many studies that have examined the associations between biomarkers of inflammation and HF have either included only those with HFrEF or did not stratify by HF subtype at all (28, 32, 35, 36). In a 2018 study (52), DuBrock et al. investigated the relationship between CRP and HFpEF ( $\geq 50 \%)$ in 216 outpatients with objective evidence of HF. They reported that CRP was 
elevated in about $60 \%$ of patients in this sample, which is much higher than in our study (40\%). This is likely because our sample was free from clinical cardiovascular disease at baseline when CRP values were measured whereas DuBrock et al.'s analysis measured CRP values in HF patients, who are already more likely to have elevated CRP (51).

Our findings also add to the research examining the race/ethnicities differences in HF and the HF subtypes, the latter being much less established. In a 2005 community cohort study (6), Galasko et al. examined ethnic differences in the prevalence and etiology of LV systolic dysfunction in 734 patients $\geq 45$ years of age. The investigators found a similar overall prevalence of LV systolic dysfunction among white and non-white participants. However, though the aim was to examine ethnic differences, the sample was primarily white $(71 \%)$ and the majority of the non-white patients were South Asian, which are more likely to have LV diastolic dysfunction (53).

In a 2008 study (32), Bahrami et al. examined race/ethnicity differences in 79 incident CHF patients after a median 4.0 years of follow-up in the MESA. African Americans were found to have the highest incidence rates of CHF and the greatest risk of developing $\mathrm{CHF}$, however, this relationship was no longer significant after adjusting for hypertension and/or diabetes. Interestingly, African Americans had the highest proportion of $\mathrm{CHF}$ that was not preceded by clinical MI $(p=0.06)$. This is interesting because African Americans have the greatest risk of MI (54) and of the two HF subtypes, previous MI is a significantly stronger risk factor for HFrEF than HFpEF (17). The present study revealed a significant increased risk of HFpEF in African Americans with elevated IL-6 but not any other race/ethnicity. Studies that have examined IL-6 across difference race/ethnicities have been contradicting $(55,56)$ and this relationship warrants further investigation. 
The predictive value of IL-6 in HFrEF was dependent on smoking status in this analysis. This is interesting since both IL-6 and smoking are associated with inflammation in HF patients $(57,58)$. Cigarette use is a well-known, strong risk factor in HFrEF, but in nonsmokers, there may be indication for IL-6 to take its place in predicting risk according to our analysis. The Health, Aging, and Body Composition Study (59), examined the predictive value of CRP, TNF$\alpha$, and IL-6 in incident HF. The investigators reported that adding IL- 6 to their risk prediction model improved the performance of the model.

Due to the sequential discovery of HFrEF and HFpEF, many early clinical trials only included those with HFrEF and the life-prolonging therapies that have been successfully implemented over the past 30 years in this subtype have not been efficacious for those with HFpEF (13). In the 2016 guidelines for the diagnosis and treatment of acute and chronic HF (13), the European Society of Cardiology stated that no treatment to date has convincingly been shown to reduce morbidity or mortality in HFpEF patients. Current treatment recommendations for HFpEF focus on managing comorbidities and alleviating symptoms, however, there is emerging evidence that inflammation might be the target for prevention intervention $(14,59)$. Cytokines themselves may be a potential therapeutic target in some patients $(60)$, however, in the prevention of HF, the role of lifestyle behaviors should also be considered. Greater achievement of the AHA's Life's Simple 7 guidelines (61) on smoking, body mass, PA, diet, cholesterol, BP, and glucose has been associated with a lower lifetime risk of HF as well as preservation of cardiac structure and function in old age. In the present study, PA levels significantly added the hs-CRP and sTNF-R1 models. Additionally, insufficient PA $(<500$ $\mathrm{MET} \cdot \mathrm{min} / \mathrm{wk}$ ) in accordance to the 2018 DHHS PA guidelines (47) was also associated with an increased risk of HF overall. Chronic exercise training has been shown to have anti- 
inflammatory effects, independent of body fat loss, in adults of any age and even with chronic conditions including HF and type 2 diabetes (62). Even acute 20-min bouts of exercise have been shown to decrease inflammatory responses via down regulation of TNF- $\alpha$ (63).

In a 2019 study, Upadhya et al. (14) reviewed several non-pharmacological interventions that have been done in HFpEF including exercise interventions. Despite exercise intolerance being a cardinal sign in HF, the exercise interventions revealed several positive outcomes including increased exercise capacity, peak oxygen consumption, quality of life and even diastolic dysfunction. Additionally, this review provides an exercise prescription for those with stable HFpEF, which could prove useful for clinicians working with HFpEF patients.

Considering the lack of effective therapies in HFpEF, this evidence underscores the importance of PA in reducing inflammation and in the prevention and treatment of $\mathrm{HF}$.

There are a few limitations to this study. Inherent to the design of the MESA to create an ethnically diverse sample, the sample is not representative of US adults, thus affecting the external validity of the results. Additionally, biomarkers of inflammation were measured at a single time point, therefore, it is unclear if elevated concentrations were indicative of acute or chronic inflammation. However, all outliers were excluded, and serial measurements of these biomarkers have been shown to add little information (64). Another limitation of this study is the small sample size among the HF samples. Additionally, only a subset of the population had measured sTNF-R1 values, which contributed to the lack of significant findings seen in this biomarker when stratified by HF subtype. Incident HF was defined as time to first HF event, therefore subsequent HF events and potential changes in EF over time were not included in the analysis. 
In summary, the results of this study suggested that elevated hs-CRP, IL-6 and sTNF-R1 are positively associated with HF risk. Elevated hs-CRP was also positively associated with risk of HFrEF and HFpEF. Elevated IL-6 predicted HFrEF among nonsmokers only and HFpEF in African Americans only. Further research is necessary to determine the pathophysiological mechanisms behind these findings and to further elucidate the associations between HFrEF and HFpEF. The combined use of various biomarkers in determining the prognosis and diagnosis of HF should also be examined. 


\section{REFERENCES}

1. Kemp CD, Conte JV. The pathophysiology of heart failure. Cardiovasc Pathol. 2012;21(5):365-71.

2. Pfeffer MA, Shah AM, Borlaug BA. Heart failure with preserved ejection fraction in perspective. Circ Res. 2019;124(11):1598-617.

3. Gladden JD, Chaanine AH, Redfield MM. Heart failure with preserved ejection fraction. Anпи Rev Med. 2018;69:65-79.

4. Komanduri S, Jadhao Y, Guduru SS, Cheriyath P, Wert Y. Prevalence and risk factors of heart failure in the USA: NHANES 2013 - 2014 epidemiological follow-up study. $J$ Community Hosp Intern Med Perspect. 2017;7(1):15-20.

5. van Riet EE, Hoes AW, Wagenaar KP, Limburg A, Landman MA, Rutten FH. Epidemiology of heart failure: the prevalence of heart failure and ventricular dysfunction in older adults over time. A systematic review. Eur J Heart Fail. 2016;18(3):242-52.

6. Galasko GI, Senior R, Lahiri A. Ethnic differences in the prevalence and aetiology of left ventricular systolic dysfunction in the community: the Harrow heart failure watch. Heart. 2005;91(5):595-600.

7. Mosterd A, Hoes AW. Clinical epidemiology of heart failure. Heart. 2007;93(9):1137-46.

8. Alehagen U, Ericsson A, Dahlström, U. Are there any significant differences between females and males in the management of heart failure? Gender aspects of an elderly population with symptoms associated with heart failure. J Card Fail. 2009;15(6):501-7.

9. Benjamin EJ, Virani SS, Callaway CW, et al. Heart disease and stroke statistics-2018 update: a report from the American Heart Association. Circulation. 2018;137(12):e67-e492. 
10. Heidenreich PA, Albert NM, Allen LA, et al. Forecasting the impact of heart failure in the United States: a policy statement from the American Heart Association. Circ Heart Fail. 2013;6(3):606-19.

11. Yancy CW, Jessup M, Bozkurt B, et al. 2013 ACCF/AHA guideline for the management of heart failure: executive summary: a report of the American College of Cardiology Foundation/American Heart Association Task Force on practice guidelines. Circulation. 2013;128(16):1810-52.

12. Herrmann G, Decherd GM. The chemical nature of heart failure. Ann Intern Med. $1939 ; 12(8): 1233-44$.

13. Ponikowski P, Voors AA, Anker SD, et al. 2016 ESC guidelines for the diagnosis and treatment of acute and chronic heart failure: The Task Force for the diagnosis and treatment of acute and chronic heart failure of the European Society of Cardiology (ESC) developed with the special contribution of the Heart Failure Association (HFA) of the ESC. Eur J Heart Fail. 2016;18(8):891-975.

14. Upadhya B, Kitzman DW. Heart failure with preserved ejection fraction: new approaches to diagnosis and management. Clin Cardiol. 2020;43(2):145-55.

15. Chioncel O, Lainscak M, Seferovic PM, et al. Epidemiology and one-year outcomes in patients with chronic heart failure and preserved, mid-range and reduced ejection fraction: an analysis of the ESC Heart Failure Long-Term Registry. Eur J Heart Fail. 2017;19(12):157485.

16. Fonarow GC, Stough WG, Abraham WT, et al. Characteristics, treatments, and outcomes of patients with preserved systolic function hospitalized for heart failure: A report from the OPTIMIZE-HF Registry. J Am Coll Cardiol. 2007;50(8):768-77. 
17. Ho JE, Enserro D, Brouwers FP, et al. Predicting heart failure with preserved and reduced ejection fraction: the international collaboration on heart failure subtypes. Circ Heart Fail. 2016;9(6):e003116.

18. Brouwers FP, de Boer RA, van der Harst P, et al. Incidence and epidemiology of new onset heart failure with preserved vs. reduced ejection fraction in a community-based cohort: 11year follow-up of PREVEND. Eur Heart J. 2013;34(19):1424-31.

19. Bursi F, Weston SA, Redfield MM, et al. Systolic and diastolic heart failure in the community. JAMA. 2006;296(18):2209-16.

20. Vasan RS, Larson MG, Benjamin EJ, Evans JC, Reiss CK, Levy D. Congestive heart failure in subjects with normal versus reduced left ventricular ejection fraction: prevalence and mortality in a population-based cohort. J Am Coll Cardiol. 1999;33(7):1948-55.

21. Kitzman DW, Gardin JM, Gottdiener JS, et al. Importance of heart failure with preserved systolic function in patients $>$ or $=65$ years of age. CHF Research Group. Cardiovascular Health Study. Am J Cardiol. 2001;87(4):413-9.

22. Devereux RB, Roman MJ, Liu JE, et al. Congestive heart failure despite normal left ventricular systolic function in a population-based sample: the Strong Heart Study. Am J Cardiol. 2000;86(10):1090-6.

23. Kupari M, Lindroos M, Iivanainen AM, Heikkilä J, Tilvis R. Congestive heart failure in old age: prevalence, mechanisms and 4-year prognosis in the Helsinki Ageing Study. J Intern Med. 1997;241(5):387-94.

24. Paulus WJ, Tschöpe C, Sanderson JE, et al. How to diagnose diastolic heart failure: a consensus statement on the diagnosis of heart failure with normal left ventricular ejection 
fraction by the heart failure and echocardiography associations of the European Society of Cardiology. Eur Heart J. 2007;28(20):2539-50.

25. Borlaug BA. Heart failure with preserved and reduced ejection fraction: different risk profiles for different diseases. Eur Heart J. 2013;34:1393-5.

26. Chow SL, Maisel AS, Anand I, et al. Role of biomarkers for the prevention, assessment, and management of heart failure: a scientific statement from the American Heart Association. Circulation. 2017;135(22):e1054-91.

27. Yancy CW, Jessup M, Bozkurt B, et al. 2017 ACC/AHA/HFSA focused update of the 2013 ACCF/AHA guideline for the management of heart failure: a report of the American College of Cardiology Foundation/American Heart Association task force on clinical practice guidelines and the heart failure society of America. Circulation. 2017;136(6):e137-61.

28. Torre-Amione G, Kapadia S, Benedict C, Oral H, Young JB, Mann DL. Proinflammatory cytokine levels in patients with depressed left ventricular ejection fraction: A report from the studies of left ventricular dysfunction (SOLVD). J Am Coll Cardiol. 1996;27(5):1201-6.

29. Wisniacki N, Taylor W, Lye M, Wilding JP. Insulin resistance and inflammatory activation in older patients with systolic and diastolic heart failure. Heart. 2005;91(1):32-7.

30. Yin WH, Chen JW, Jen HL, et al. Independent prognostic value of elevated high-sensitivity C-reactive protein in chronic heart failure. Am Heart J. 2004;147(5):931-8.

31. Katz SD, Rao R, Berman JW, et al. Pathophysiological correlates of increased serum tumor necrosis factor in patients with congestive heart failure. Relation to nitric oxide-dependent vasodilation in the forearm circulation. Circulation. 1994;90(1):12-6. 
32. Bahrami H, Kronmal R, Bluemke DA, et al. Differences in the incidence of congestive heart failure by ethnicity: the multi-ethnic study of atherosclerosis. Arch Intern Med. 2008;168(19):2138-45.

33. Vasan RS, Levy D. Defining diastolic heart failure: a call for standardized diagnostic criteria. Circulation. 2000;101(17):2118-21.

34. Cainzos-Achirica M, Miedema MD, McEvoy JW, et al. The prognostic value of high sensitivity C-reactive protein in a multi-ethnic population after more than 10 years of followup: the multi-ethnic study of atherosclerosis (MESA). Int J Cardiol. 2018;264:158-64.

35. Cesari M, Penninx BW, Newman AB, et al. Inflammatory markers and onset of cardiovascular events: results from the health ABC study. Circulation. 2003;108(19):231722.

36. Deswal A, Petersen NJ, Feldman AM, Young JB, White BG, Mann DL. Cytokines and cytokine receptors in advanced heart failure. Circulation. 2001;103(16):2055-9.

37. Michowitz Y, Arbel Y, Wexler D, et al. Predictive value of high sensitivity CRP in patients with diastolic heart failure. Int J Cardiol. 2007;125(3):347-51.

38. Tsutamoto T, Hisanaga T, Wada A, et al. Interleukin-6 spillover in the peripheral circulation increases with the severity of heart failure, and the high plasma level of interleukin-6 is an important prognostic predictor in patients with congestive heart failure. J Am Coll Cardiol. $1998 ; 31(2): 391-8$

39. Dutka DP, Elborn JS, Delamere F, Shale DJ, Morris GK. Tumour necrosis factor alpha in severe congestive cardiac failure. Br Heart J. 1993;70(2):141-3.

40. Ferrari R, Bachetti T, Confortini R, et al. Tumor necrosis factor soluble receptors in patients with various degrees of congestive heart failure. Circulation. 1995;92(6):1479-86. 
41. Mocan M, Mocan Hognogi LD, Anton FP, et al. Biomarkers of inflammation in left ventricular diastolic dysfunction. Dis Markers. 2019;2019:7583690-14.

42. Carnes J, Gordon G. Biomarkers in heart failure with preserved ejection fraction: An update on progress and future challenges. Heart Lung Circ. 2020;29(1):62-8.

43. Bild DE, Bluemke DA, Burke GL, et al. Multi-Ethnic Study of Atherosclerosis: objectives and design. Am J Epidemiol. 2002;156(9):871-81.

44. National Institutes of Health/National Health Lung and Blood Institute: Biologic Specimen and Data Repository Information Coordinating Center. In: BIOLINCC. https://biolincc.nhlbi.nih.gov/home/.

45. MESA Coordinating Center. MESA manual of operations: field center and laboratory procedures. [cited 2020 Apr 16]. Available from http://www.mesanhlbi.org/publicDocs/MesaMop/MesaMop1-5-01.doc.

46. Pearson TA, Mensah GA, Alexander RW, et al. Markers of inflammation and cardiovascular disease: application to clinical and public health practice: A statement for healthcare professionals from the centers for disease control and prevention and the American Heart Association. Circulation. 2003;107(3):499-511.

47. U.S. Department of Health and Human Services. Physical activity guidelines for Americans. 2nd ed. Washington, DC: U.S. Department of Health and Human Services; 2018.

48. National Cholesterol Education Program (NCEP) Expert Panel on Detection, Evaluation, and Treatment of High Blood Cholesterol in Adults (Adult Treatment Panel III). JAMA. 2001;285(19):2486-97.

49. SAS Institute Inc. 2016. Base $S A S_{\circledast} 9.4$ Procedures Guide: Statistical Procedures, Sixth Edition. Cary, NC: SAS Institute Inc. 
50. van Kimmenade RR, Januzzi JL Jr. Emerging biomarkers in heart failure. Clin Chem. 2012;58(1):127-38.

51. Bozkurt B, Mann DL, Deswal A. Biomarkers of inflammation in heart failure. Heart Fail Rev. 2010;15(4):331-41.

52. DuBrock HM, AbouEzzeddine OF, Redfield MM. High-sensitivity C-reactive protein in heart failure with preserved ejection fraction. PloS One. 2018;13(8):e0201836.

53. Yip GW, Ho PP, Woo KS, Sanderson JE. Comparison of frequencies of left ventricular systolic and diastolic heart failure in Chinese living in Hong Kong. Am J Cardiol. 1999;84(5):563-7.

54. Graham G. Racial and ethnic differences in acute coronary syndrome and myocardial infarction within the united states: from demographics to outcomes. Clin Cardiol. 2016;39(5):299-306.

55. Allison MA, Criqui MH, McClelland RL, et al. The effect of novel cardiovascular risk factors on the ethnic-specific odds for peripheral arterial disease in the multi-ethnic study of atherosclerosis (MESA). J Am Coll Cardiol. 2006;48(6):1190-7.

56. Yaffe K, Lindquist K, Penninx BW, et al. Inflammatory markers and cognition in wellfunctioning African-American and white elders. Neurology. 2003;61(1):76-80.

57. Yan AT, Yan RT, Cushman M, et al. Relationship of interleukin-6 with regional and global left-ventricular function in asymptomatic individuals without clinical cardiovascular disease: insights from the multi-ethnic study of atherosclerosis. Eur Heart J. 2010;31(7):875-82.

58. Gopal DM, Kalogeropoulos AP, Georgiopoulou VV, et al. Cigarette smoking exposure and heart failure risk in older adults: the health, aging, and body composition study. Am Heart J. 2012;164(2):236-42. 
59. Kalogeropoulos A, Georgiopoulou V, Kritchevsky SB, et al. Epidemiology of incident heart failure in a contemporary elderly population: the health, aging, and body composition study. Arch Intern Med. 2009;169(7):708-15.

60. Dibbs Z, Kurrelmeyer K, Kalra D, et al. Cytokines in heart failure: pathogenetic mechanisms and potential treatment. Proc Assoc Am Physicians. 1999;111(5):423-8.

61. Folsom AR, Shah AM, Lutsey PL, et al. American Heart Association's Life's Simple 7: avoiding heart failure and preserving cardiac structure and function. Am J Med. 2015;128(9):970-6.

62. Flynn MG, McFarlin BK, Markofski MM. The anti-inflammatory actions of exercise training. Am J Lifestyle Med. 2007;1(3):220-35.

63. Dimitrov S, Hulteng E, Hong S. Inflammation and exercise: Inhibition of monocytic TNF production by acute exercise via $\beta 2$-adrenergic activation. Brain Behav Immun. 2017;61:608.

64. Kalogeropoulos A, Georgiopoulou V, Psaty BM, et al. Inflammatory markers and incident heart failure risk in older adults: The health ABC (health, aging, and body composition) study. J Am Coll Cardiol. 2010;55(19):2129-37. 
Appendices 


\section{Appendix A}

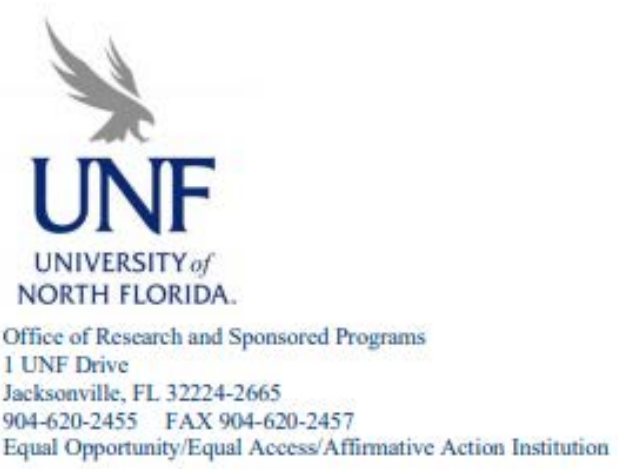

\section{MEMORANDUM}

DATE: $\quad$ March 30,2020

TO: $\quad$ Ms. Michelle Stone

VIA: $\quad$ Dr. James Churilla

DEPT: $\quad$ Clinical \& Applied Movement Sciences

FROM: Dr. Jennifer Wesely, Chairperson

UNF Institutional Review Board

RE: Review conducted on behalf of the UNF Institutional Review Board

"Biomarkers of Inflammation in Heart Failure Patients with Reduced and Preserved

Ejection Fractions: Multi-Ethnic Study of Atherosclerosis"

This is to advise you that your project, "Biomarkers of Inflammation in Heart Failure Patients with Reduced and Preserved Ejection Fractions: Multi-Ethnic Study of Atherosclerosis," was reviewed on behalf of the UNF Institutional Review Board and was declared "not research involving human subjects" based on the definitions provided in the U.S. Department of Health and Human Services Code of Federal Regulations found at 45 CFR 46.102. As such, this project qualifies for a Waiver of IRB Review.

Please note, this waiver does not absolve the Principal Investigator from complying with other federal, state, or local laws or institutional policies and procedures that may be applicable in the conduct of this project.

This waiver applies to your project in the form and content as submitted to the IRB for review. Any variations or modifications to this project involving the participation of human subjects must be approved by the IRB prior to implementing such changes. Please maintain a copy of this waiver for your records.

Thank you for submitting your project to the IRB for consideration. Should you have any questions or if we can be of further assistance, please contact the Research Integrity office at 904-620-2455, or IRB@unf.edu. 


\begin{abstract}
Vita
Michelle L. Stone is a graduate teaching and research assistant in the Clinical and Applied Movement Sciences department at the University of North Florida (UNF) in Jacksonville, FL. There, she recently completed her master's degree in Exercise Science and Chronic Disease. Upon earning her Bachelor of Science in Health degree from UNF in 2014, where she majored in Exercise Science and graduated with Summa Cum Laude honors, she completed an internship in Durham, North Carolina at the Duke Molecular Physiology Institute and successfully obtained certification as an Exercise Physiologist from the American College of Sport's Medicine.

Originally from West Sacramento, California, Michelle currently lives in Jacksonville, FL with her partner, Travis, her cat, Duchess, and their dog, Nala. Her research interests consist of cardiovascular health, heart failure, physical activity, and translational research. Her future ambitions include attending medical school to help spread the knowledge of exercise science related research and implement this literature into her own practice and research endeavors.
\end{abstract}

